\title{
Untangling causality in midlatitude aerosol-cloud adjustments
}

\author{
Daniel T. McCoy ${ }^{1, a}$, Paul Field ${ }^{1,2}$, Hamish Gordon ${ }^{1,3}$, Gregory S. Elsaesser ${ }^{4,5}$, and Daniel P. Grosvenor ${ }^{1,6}$ \\ ${ }^{1}$ Institute for Climate and Atmospheric Science, University of Leeds, Leeds, UK \\ ${ }^{2}$ Met Office, Fitzroy Rd, Exeter, UK \\ ${ }^{3}$ Engineering Research Accelerator, Carnegie Mellon University, Forbes Avenue, Pittsburgh, PA, USA \\ ${ }^{4}$ Department of Applied Physics and Applied Mathematics, Columbia University, New York, NY, USA \\ ${ }^{5}$ NASA Goddard Institute for Space Studies, New York, NY, USA \\ ${ }^{6}$ National Centre for Atmospheric Science, Leeds, UK \\ ${ }^{a}$ now at: Department of Atmospheric Science, University of Wyoming, Laramie, WY 82071, USA
}

Correspondence: Daniel T. McCoy (d.t.mccoy@leeds.ac.uk)

Received: 23 July 2019 - Discussion started: 26 August 2019

Revised: 3 February 2020 - Accepted: 12 February 2020 - Published: 6 April 2020

\begin{abstract}
Aerosol-cloud interactions represent the leading uncertainty in our ability to infer climate sensitivity from the observational record. The forcing from changes in cloud albedo driven by increases in cloud droplet number $\left(N_{\mathrm{d}}\right)$ (the first indirect effect) is confidently negative and has narrowed its probable range in the last decade, but the sign and strength of forcing associated with changes in cloud macrophysics in response to aerosol (aerosol-cloud adjustments) remain uncertain. This uncertainty reflects our inability to accurately quantify variability not associated with a causal link flowing from the cloud microphysical state to the cloud macrophysical state. Once variability associated with meteorology has been removed, covariance between the liquid water path (LWP) averaged across cloudy and clear regions (here characterizing the macrophysical state) and $N_{\mathrm{d}}$ (characterizing the microphysical) is the sum of two causal pathways linking $N_{\mathrm{d}}$ to LWP: $N_{\mathrm{d}}$ altering LWP (adjustments) and precipitation scavenging aerosol and thus depleting $N_{\mathrm{d}}$. Only the former term is relevant to constraining adjustments, but disentangling these terms in observations is challenging. We hypothesize that the diversity of constraints on aerosol-cloud adjustments in the literature may be partly due to not explicitly characterizing covariance flowing from cloud to aerosol and aerosol to cloud. Here, we restrict our analysis to the regime of extratropical clouds outside of low-pressure centers associated with cyclonic activity. Observations from MAC-LWP (Multisensor Advanced Climatology of Liquid Water Path) and MODIS are compared to simulations in the Met Office Unified Model (UM) GA7.1 (the atmosphere model of
\end{abstract}

HadGEM3-GC3.1 and UKESM1). The meteorological predictors of LWP are found to be similar between the model and observations. There is also agreement with previous literature on cloud-controlling factors finding that increasing stability, moisture, and sensible heat flux enhance LWP, while increasing subsidence and sea surface temperature decrease it. A simulation where cloud microphysics are insensitive to changes in $N_{\mathrm{d}}$ is used to characterize covariance between $N_{\mathrm{d}}$ and LWP that is induced by factors other than aerosol-cloud adjustments. By removing variability associated with meteorology and scavenging, we infer the sensitivity of LWP to changes in $N_{\mathrm{d}}$. Application of this technique to UM GA7.1 simulations reproduces the true model adjustment strength. Observational constraints developed using simulated covariability not induced by adjustments and observed covariability between $N_{\mathrm{d}}$ and LWP predict a $25 \%-30 \%$ overestimate by the UM GA7.1 in LWP change and a 30\%-35\% overestimate in associated radiative forcing.

\section{Introduction}

Uncertainty in the radiative forcing due to aerosol-cloud interactions is the leading uncertainty limiting our ability to accurately diagnose the Earth's climate sensitivity from the observational record (Forster, 2016). The best estimate of the radiative forcing due to aerosol-cloud interactions (also called the first indirect effect; Twomey, 1977) has narrowed to -1.2 to $-0.34 \mathrm{~W} \mathrm{~m}^{-2}$ in a recent survey of forc- 
ing from aerosol-cloud interactions (Storelvmo, 2017; Bellouin et al., 2020), but the sign and strength of the forcing due to changes in cloud macrophysical properties in response to aerosol (aerosol-cloud adjustments) remain uncertain (Bellouin et al., 2020). This uncertainty reflects the difficulty in disentangling the many factors that determine cloud macrophysical properties. Unlike cloud droplet number concentration $\left(N_{\mathrm{d}}\right)$, which is primarily driven by the availability of suitable aerosol, cloud macrophysical properties are primarily determined by the state of the atmosphere but may be modulated by $N_{\mathrm{d}}$ (Stevens and Feingold, 2009).

Here, we focus on liquid clouds. Within liquid clouds two main processes are hypothesized to alter cloud liquid content in response to changes in $N_{\mathrm{d}}$. As $N_{\mathrm{d}}$ is increased the following may occur: (1) a suppression of precipitation by enhanced $N_{\mathrm{d}}$ (Albrecht, 1989; Pincus and Baker, 1994) and (2) strengthened entrainment of dry air (Ackerman et al., 2004; Bretherton et al., 2007; Wang et al., 2003; Xue and Feingold, 2006). These processes drive the liquid content of cloud in opposite directions following a perturbation in microphysics, further complicating the interpretation of covariability between cloud macrophysical and microphysical properties. Because these processes exist at a timescale and length scale far below those resolved in climate models, they must be parameterized, resulting in substantial uncertainty. Because of this, constraining the cloud macrophysical response to changes in cloud microphysics using observations is an essential step towards constraining aerosol forcing. Aerosol-cloud adjustments are likely to contribute a relatively small fraction of overall variability in cloud macrophysical properties (Bender et al., 2019) - making the data volume available from remote-sensing observations particularly relevant to providing an observational constraint by detecting the small signal from aerosol-cloud adjustments hidden in meteorologically induced cloud variability. The literature has produced numerous careful analyses of the observational record, but these analyses have produced divergent estimates of the aggregate effect of increased $N_{\mathrm{d}}$ on liquid clouds. These impacts range from increased $N_{\mathrm{d}}$ increasing liquid content in clouds (Chen et al., 2014; Rosenfeld et al., 2019) to almost no response in in-cloud and area-averaged liquid water path (LWP; Toll et al., 2017; Malavelle et al., 2017) and to decreasing liquid content (Gryspeerdt et al., 2019; Sato et al., 2018; Toll et al., 2019). In contrast, the response in cloud cover to $N_{\mathrm{d}}$ has tended to be consistently inferred as producing a forcing equal to or larger than the first indirect effect (Gryspeerdt et al., 2016; Christensen et al., 2017; Andersen et al., 2017). A simulation of deep, opencellular boundary layers has shown an increase in the cloud fraction and a decrease in in-cloud LWP, ultimately resulting in an increase in reflected shortwave in the simulation (Possner et al., 2018). Given the wide range of potential observational constraints it remains difficult to offer advice on the cloud microphysical parameterizations that are the most realistic.
However, the causal link flowing from $N_{\mathrm{d}}$ to clouds is not the only mechanism relating cloud macrophysics to cloud microphysics. As shown in Wood et al. (2012), the spatial pattern in $N_{\mathrm{d}}$ observed in nature is primarily determined by precipitation scavenging. That is to say, $N_{\mathrm{d}}$ may both alter cloud macrophysical properties and be altered by them, and interpreting observations as a constraint on only microphysical to macrophysical causality is erroneous, as discussed in Gryspeerdt et al. (2019). To be able to constrain cloud responses to aerosol-driven changes in $N_{\mathrm{d}}$ we must be able to characterize the effects of cloud macrophysical properties on $N_{\mathrm{d}}$ (by precipitation scavenging) and covariability between $N_{\mathrm{d}}$ and LWP induced by confounding factors such as the relative location of aerosol sources and climatological cloud cover or meteorological modulation of aerosol and clouds.

Bender et al. (2019) proposed utilizing the observed covariance between $N_{\mathrm{d}}$ and LWP as an aggregate measure of aerosol-cloud-radiation behavior across climate models and reanalyses. For a model to be able to realistically reproduce aerosol-cloud behavior one precondition is that covariance flowing from clouds to aerosol and from aerosol to clouds as well as the non-causal covariance induced by air mass history must result in total covariance consistent with observations. Similarly, Gryspeerdt et al. (2019) examined covariance between $N_{\mathrm{d}}$ and in-cloud LWP but proposed to separate variability induced by adjustments from other sources of covariability by using clustering on global data. This study follows these earlier studies and attempts to partition covariance between LWP and $N_{\mathrm{d}}$ related to causality flowing from $N_{\mathrm{d}}$ to LWP from other covariance. We utilize empirical analysis of observations and model output to try to disentangle variability driven by meteorological "cloud-controlling factors" (Stevens and Brenguier, 2009) and variability related to changes in cloud microphysics. Within this framework we focus on the midlatitudes. Previous work has performed similar analysis on cyclonic midlatitude systems, finding a distinct increase in LWP at a fixed precipitation rate (McCoy et al., 2018b). These large synoptic systems account for roughly half of the midlatitudes (Bodas-Salcedo et al., 2014). Here, we turn our attention to the remaining interstitial regions between cyclones. This regime tends to be less cloudy, have an overall lower albedo, and have a lower cloud optical depth (an example is shown in Fig. 1a). Thus, while these regions do not host dramatic fronts and cloud shields, changes in their liquid cloud due to anthropogenic aerosol may contribute strongly to the overall aerosol forcing because cloud areal coverage and cloud optical depth are further below saturation. 
(a) Example cyclone composite

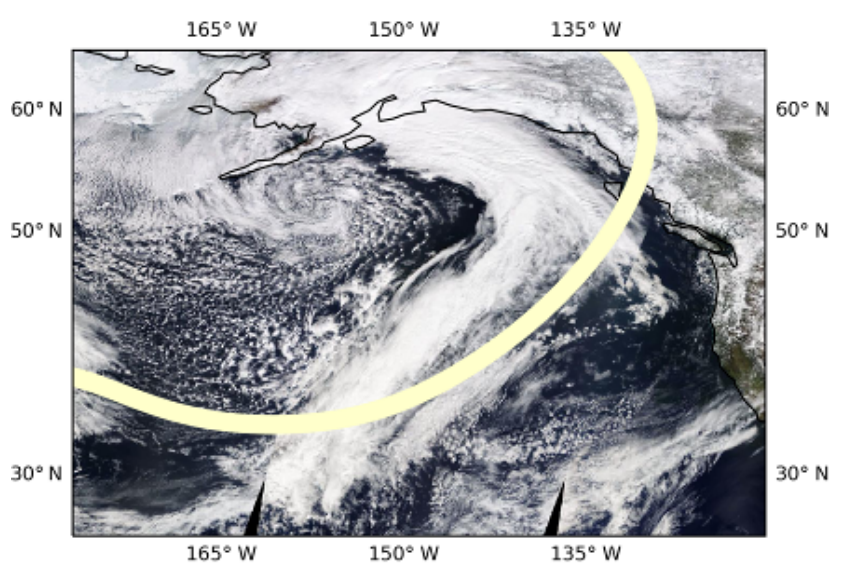

(b) Fraction of data outside of cyclones over water

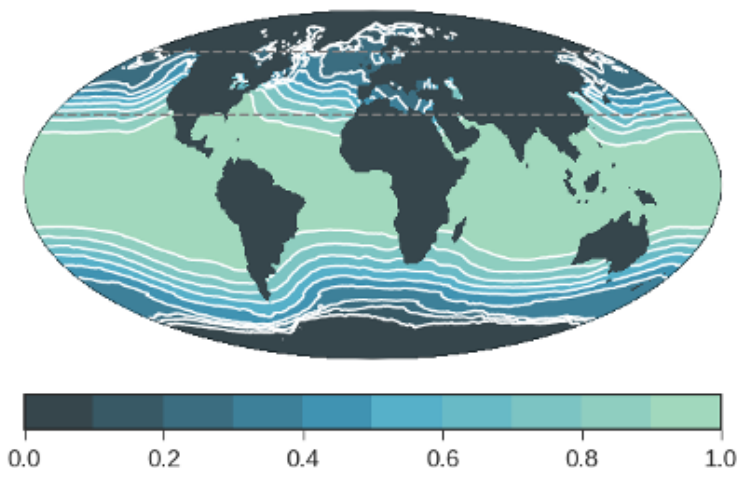

Figure 1. (a) An example of a cyclone off the coast of North America from MODIS Aqua. The cyclone center has been identified south of the Aleut Peninsula based on MERRA-2 sea-level pressure (SLP). A line shows the edge of the area considered to lie within the cyclone following Field and Wood (2007). (b) The fraction of data outside of cyclones averaged between 2003 and 2015. The mean within the $30-60^{\circ} \mathrm{N}$ region is $42 \%$.

\section{Methods}

\subsection{Region and variable selection}

The empirical analysis on both observational and simulated data in this work follows pioneering studies investigating meteorological controls on subtropical (Myers and Norris, 2013, 2015; Qu et al., 2015; Klein et al., 2017; Seethala et al., 2015) and midlatitude (Miyamoto et al., 2018) marine boundarylayer cloudiness. The selection of variables used in this study is based on the findings of these earlier studies. The predictors examined here are sea surface temperature (SST), largescale subsidence $(\omega)$ at $550 \mathrm{hPa}$, the strength of the inversion at the top of the boundary layer (estimated inversion strength - EIS - as defined in Wood and Bretherton, 2006), the total water vapor path (WVP), and sensible heat flux (SHF). A summary is given in Table 1. A priori we expect that increasing SSTs should lead to decreasing cloudiness (My- ers and Norris, 2015; Qu et al., 2015; McCoy et al., 2017; Bretherton and Blossey, 2014). Increasing subsidence should decrease the liquid water path (Myers and Norris, 2013). Increasing inversion strength should lead to an increasing cloud fraction (Wood and Bretherton, 2006; Klein and Hartmann, 1993; Qu et al., 2015; Myers and Norris, 2015; Seethala et al., 2015). As shown in Miyamoto et al. (2018) from examination of midlatitude ocean fronts, increased SHF should increase cloudiness. Finally, while less extensively studied, an overall increase in WVP seems likely to lead to increased cloudiness as the atmospheric column moisture increases, holding all else equal (McCoy et al., 2019).

The central goal of this study is to develop an empirical constraint on aerosol-cloud adjustments. However, direct measurements of the aerosol state to constrain aerosol-cloud adjustments have been found to be sensitive to errors in pristine conditions (Ma et al., 2018). To develop a constraint on aerosol-cloud adjustments we examine the cloud microphysical state in addition to the meteorological parameters listed above. Cloud droplet number concentration is the state variable relating cloud macrophysics to aerosol concentration (Wood, 2012; Grosvenor et al., 2018) and is the predictor used in this study to characterize aerosol-cloud adjustments.

We hasten to note that the list of predictors described above is not intended to be complete (that is to say, we do not anticipate that we will be able to explain $100 \%$ of the variability in clouds with these predictors). Our goal is to explain enough variability with these predictors to be able to infer statistically robust relationships between cloud macrophysical and microphysical properties in the variance unexplained by meteorological variability. The predictive ability of these inferred relationships will be tested within the context of a global climate model (GCM).

Having discussed predictors, we will now discuss predictands. Outside of cyclones cloud cover is primarily liquid, boundary-layer cloud, which substantially affects shortwave radiation but has little effect on longwave radiation (Hartmann and Short, 1980). Thus, we focus on the liquid water path (LWP) averaged over cloudy and clear regions. This variable allows observations and model output to be compared without needing to simulate output from a passive spectroradiometer (Bodas-Salcedo et al., 2011) or considering cloud overlap, as would be required for in-cloud LWP.

Analysis is carried out in the Northern Hemisphere (here $30-60^{\circ} \mathrm{N}$ ) over oceans. This choice has been made for several reasons: first, there is a large variability in $N_{\mathrm{d}}$ across the northern midlatitudes that is not strongly driven by the seasonal cycle. In the Southern Ocean cloud condensation nuclei $(\mathrm{CCN})$ variability is primarily due to biogenic sources, and their variability is strongly driven by the seasonal cycle, making analysis in the context of meteorological controls difficult to interpret (Ayers and Gras, 1991; McCoy et al., 2015a; Charlson et al., 1987). Second, Southern Ocean $N_{\mathrm{d}}$ is still poorly represented in the Met Office Unified Model GA7.1 (discussed in Sect. 2.4), with both too low a mean 
Table 1. List of observed variables.

\begin{tabular}{|c|c|c|}
\hline Variable & Description & Source \\
\hline LWP & Microwave liquid water path averaged over cloudy and clear sky. & Elsaesser et al. (2017) \\
\hline$N_{\mathrm{d}}$ & MODIS cloud droplet number concentration. & $\begin{array}{l}\text { McCoy et al. (2018b), Grosvenor and } \\
\text { Wood (2014) }\end{array}$ \\
\hline SST & $\begin{array}{l}\text { OSTIA sea surface temperature as used by MERRA- } 2 \text { reanalysis as a boundary } \\
\text { condition. }\end{array}$ & Molod et al. (2015) \\
\hline WVP & Column water vapor path as observed by MAC-LWP. & Elsaesser et al. (2017) \\
\hline$\omega_{550}$ & $550 \mathrm{hPa}$ subsidence calculated by MERRA- 2 . & Molod et al. (2015) \\
\hline EIS & $\begin{array}{l}\text { Estimated inversion strength calculated following Wood and Bretherton (2006) } \\
\text { using MERRA-2 data. }\end{array}$ & $\begin{array}{l}\text { Molod et al. (2015), Wood and Brether- } \\
\text { ton (2006) }\end{array}$ \\
\hline SHF & $\begin{array}{l}\text { Sensible heat flux calculated from MERRA-2 data following Miyamoto } \\
\text { et al. (2018). }\end{array}$ & Molod et al. (2015) \\
\hline
\end{tabular}

value and generally too small a seasonal cycle - in contrast to the Northern Hemisphere, which compares well with observations (Mulcahy et al., 2018).

\subsection{Outside of cyclone compositing}

The passage of synoptic systems is the central mode of variability in midlatitude cloudiness. McCoy et al. (2018b) focused on cyclone systems and showed that once meteorological variability was accounted for, the effects of changes in cloud microphysics driven by changes in $N_{\mathrm{d}}$ on liquid content are revealed. This work utilized the Field and Wood (2007) cyclone compositing algorithm, which uses sea-level pressure (SLP) to identify cyclone centers. Here we utilize the same compositing approach but focus on all data that are $2000 \mathrm{~km}$ away from a cyclone center, following BodasSalcedo et al. (2014). This separates the midlatitudes into times when a cyclone is nearby and when there is no cyclone nearby. Once cyclone centers are identified all data within $2000 \mathrm{~km}$ of an identified cyclone center are masked out of the data set. All data over land are also masked because microwave observations are unavailable (see next section).

A schematic representation of the frequency of occurrence of out-of-cyclone states is shown in Fig. $1 \mathrm{~b}$ and is $42 \%$ in the $30-60^{\circ} \mathrm{N}$ region focused on in this study. All data are regridded to a common $1^{\circ} \times 1^{\circ}$ spatial resolution before analysis. All data are daily mean, except for observed $N_{\mathrm{d}}$, which is only available for the MODIS Aqua overpass; however the diurnal cycle of $N_{\mathrm{d}}$ is thought to be relatively slight (Dong et al., 2014), and it is unlikely that this retrieval limitation significantly impacts our results. Our choice of resolution is motivated by the natural resolution of the Multisensor Advanced Climatology of Liquid Water Path (MAC-LWP) data set. Performing the analysis with a coarser resolution might change the regression coefficients derived in Sect. 2.5, as has been reported for analysis of the first indirect effect (McComiskey and Feingold, 2012). However, in Sect. 3.4 we validate the adjustments inferred from this resolution against the true adjustments in Met Office Unified Model (UM) GA7.1 (the atmosphere model of HadGEM3-GC3.1 and UKESM1) and find agreement, which demonstrates that our choice of resolution does not affect our results.

\subsection{Observations}

The cloud liquid water path (LWP) is calculated based on the aggregated observations from multiple satellite microwave sensors following the methodology of the multisensor advanced climatology of LWP (MAC-LWP; Elsaesser et al., 2017) at a daily mean resolution. Microwave radiometers are sensitive to total liquid. This means that the retrieval must calculate a partitioning between precipitating and nonprecipitating liquid. Here, the liquid water path in clouds is calculated following Elsaesser et al. (2017). Previous analysis has shown that the midlatitude partitioning of rain and cloud in MAC-LWP compares favorably with convectionpermitting simulations (McCoy et al., 2018b). The MACLWP data set estimates that $7 \%$ of total liquid path is rain in the NH midlatitudes outside of cyclones. Because of the low fraction of rainwater in the midlatitudes outside of cyclones it is unlikely that the need to partition the observations into rain and cloud water substantially affects observational constraints as calculated in Sect. 3.3. The liquid water path is defined as the average of cloudy and clear regions and is insensitive to overlying ice cloud (unlike passive optical retrievals). This definition of LWP is consistent with the definition from GCMs. Microwave retrievals are only available over the ocean.

Observations of $N_{\mathrm{d}}$ are calculated based on MODIS observations of cloud optical depth and droplet effective radius. Level 2 swath data (joint product) from MODIS collection 5.1 (King et al., 2003) are filtered by removing pixels with solar zenith angles greater than $65^{\circ}$ to eliminate problematic retrievals at a pixel level (Grosvenor and Wood, 2014). The daily mean $N_{\mathrm{d}}$ at $1^{\circ} \times 1^{\circ}$ resolution is calculated from the filtered level 2 swath data and only low (cloud tops below $3.2 \mathrm{~km}$ ), liquid clouds were used to calculate $N_{\mathrm{d}}$. Only $1^{\circ} \times 1^{\circ}$ regions where the liquid cloud fraction exceeds $80 \%$ 
are considered valid (Bennartz et al., 2011), and the $N_{\mathrm{d}}$ is calculated using the effective radius from the $3.7 \mu \mathrm{m}$ MODIS channel. This data set is evaluated in Grosvenor et al. (2018) and in McCoy et al. (2018a), where it shows consistency with measurements from aircraft.

We feel that this combination of radiometers in constraining adjustments is particularly advantageous because there is no shared information between the microwave retrieval of LWP and the shortwave and near-infrared retrieval of $N_{\mathrm{d}}$. This is in contrast to the common practice of utilizing MODIS retrievals of cloud droplet effective radius and optical depth to calculate both the in-cloud LWP and $N_{\mathrm{d}}$, making it conceptually difficult to cleanly infer changes in LWP due to changes in $N_{\mathrm{d}}$.

The meteorological state of the atmosphere is characterized using reanalysis from MERRA-2 (Molod et al., 2015) and microwave observations of WVP from MAC-LWP. The period during which all of these observations are available stretches from 2003 to 2015. A list of variables and data sources is given in Table 1 .

\subsection{Simulations}

Simulations are carried out in atmosphere-only simulations in the UM version 10.8 at N96 horizontal resolution. The version of the atmosphere model is GA7.1 coupled to the UKCA (UK Chemistry and Aerosols) model as described in (Mulcahy et al., 2018). The GA7.1 atmosphere model is the physical basis for the atmosphere model included in the HadGEM3-GC3.1 and UKESM1 climate model submission to CMIP6 (Walters et al., 2019). All simulations are run for 2 years and 3 months, starting in September 2013. Simulations are nudged to European Centre for Medium-Range Weather Forecasts (ECMWF) reanalysis winds above model level 16 (approximately $1.8 \mathrm{~km}$ ). Paired simulations are conducted with emissions of aerosol and precursor gases set to preindustrial (henceforth labeled PI) and to present-day (labeled PD) levels. Anthropogenic emissions use the CMIP6 inventory (Eyring et al., 2016), natural emissions over land use the MEGAN-MACC inventory (Sindelarova et al., 2014), and natural emissions over the ocean follow the POET inventory (Granier et al., 2005). These simulations are conducted to calculate the response of cloud to anthropogenic aerosol. Additional sensitivity studies were carried out, starting with nudging at level 27 (approximately $5 \mathrm{~km}$ ) and without nudging. In the latter case simulations of the PI and PD were run for 10 years and 3 months, starting in September 2003. The results of this analysis are shown in the Supplement and do not differ substantially from the results in the main text.

In GA7.1 aerosol number concentration has the potential to affect cloud microphysics in three places: first, the conversion of cloud water to rain, where enhanced $N_{\mathrm{d}}$ suppresses the conversion of cloud water to rainwater. This is parameterized using the scheme in Khairoutdinov and Kogan (2000), bias corrected as described in Boutle et al. (2014). The con- version rate of cloud to rain is parameterized as

$P_{\text {Cloud } \rightarrow \text { Rain }} \propto q_{\text {Cloud }}^{2.47} \cdot N_{\mathrm{d}}^{-1.79}$,

where $q_{\text {Cloud }}$ is the cloud liquid water mixing ratio. Second, it can affect cloud microphysics in the gravitational settling of cloud droplets, where enhanced $N_{\mathrm{d}}$ suppresses the settling of cloud droplets out of the cloud. The flux of water settling out of a cloud layer is given as

$P_{\text {Settle }} \propto q_{\text {Cloud }}^{5 / 3} N_{\mathrm{d}}^{-2 / 3}$.

Third, it can affect cloud albedo through changes in $N_{\mathrm{d}}$ (Twomey, 1977).

However, clouds may affect aerosol concentrations via wet scavenging. UKCA allows scavenging to be configured in two ways: the default configuration or using the scavenging coefficients in the ECHAM5-HAM model (Stier et al., 2005). To evaluate some of the uncertainty related to scavenging we perform simulations with both sets of coefficients. A list of model simulations conducted is given in Table 2 .

\subsection{Analyzing covariance in the system}

Our goal in this paper is to characterize how $N_{\mathrm{d}}$ drives LWP. However, to reveal robust correlations between $N_{\mathrm{d}}$ and LWP, meteorological variability must be accounted for. To achieve this we follow previous empirical analysis of cloudcontrolling factors and utilize multiple linear regression to characterize the dependence of various cloud properties as predictands on the predictors described above (Myers and Norris, 2015). As with all empirical analyses of observations, correlation between predictors and the predictand does not necessarily mean that they are causally linked. The meteorological predictors selected here have had mechanisms hypothesized to link them to cloud variability. Another issue with this and similar analyses of the response of cloud to cloud-controlling factors is that thermodynamic and dynamical predictors within the Earth's atmosphere are correlated (McCoy et al., 2017; Myers and Norris, 2015, 2013). As the variance shared by predictors grows, the uncertainty in the coefficients calculated by multiple linear regression increases. While this is an issue, it is inescapable in trying to disentangle the effects of different cloud-controlling factors on cloud properties. Examples of meteorological variables that are correlated but have opposing effects on cloud cover include subsidence and stability and stability and SST (Myers and Norris, 2013; Qu et al., 2015; Wall et al., 2017).

To reduce predictor covariance we bin our $1^{\circ} \times 1^{\circ}$ daily mean data from model output and observations into the space of SST and WVP. All output over oceans is considered in the analysis. We choose these predictors to bin our data before performing regression analysis because they represent two of the most basic meteorological state variables, because they covary strongly, and because LWP varies significantly as a function of WVP and SST in both observations 
Table 2. List of simulations: the Met Office model designation; a short description; the scavenging coefficients used; the value of $N_{\mathrm{d}}$ used in the radiation, settling, and autoconversion parameterizations; and aerosol emissions period used (present day - PD - or preindustrial - PI). A tilde in $N_{\mathrm{d}}$ for a given parameterization indicates that $N_{\mathrm{d}}$ was not set to a constant value.

\begin{tabular}{|c|c|c|c|c|c|c|}
\hline Model label & Description & Scavenging & $\begin{array}{r}\text { Radiation } N_{\mathrm{d}} \\
\left(\mathrm{cm}^{-3}\right)\end{array}$ & $\begin{array}{r}\text { Settling } N_{\mathrm{d}} \\
\quad\left(\mathrm{cm}^{-3}\right)\end{array}$ & $\begin{array}{r}\text { Autoconversion } N_{\mathrm{d}} \\
\left(\mathrm{cm}^{-3}\right)\end{array}$ & Emissions \\
\hline u-bh860 & Control & UM & $\sim$ & $\sim$ & $\sim$ & PD \\
\hline u-bi580 & Control & ECHAM & $\sim$ & $\sim$ & $\sim$ & PD \\
\hline u-bi674 & Scavenging only & UM & 75 & 75 & 75 & PD \\
\hline u-bi677 & Scavenging only & ECHAM & 75 & 75 & 75 & PD \\
\hline u-bh861 & Control with PI aerosol & UM & $\sim$ & $\sim$ & $\sim$ & PI \\
\hline u-bo314 & Control with PI aerosol & ECHAM & $\sim$ & $\sim$ & $\sim$ & PI \\
\hline u-bi239 & Cloud microphysics $N_{\mathrm{d}}=30$ & UM & 30 & 30 & 30 & PD \\
\hline u-bi971 & Cloud microphysics $N_{\mathrm{d}}=100$ & UM & 100 & 100 & 100 & PD \\
\hline u-bi972 & Cloud microphysics $N_{\mathrm{d}}=300$ & UM & 300 & 300 & 300 & PD \\
\hline u-bi284 & Autoconversion $N_{\mathrm{d}}=100$ & UM & 30 & 30 & 100 & PD \\
\hline u-bi285 & Autoconversion $N_{\mathrm{d}}=300$ & UM & 30 & 30 & 300 & PD \\
\hline u-bi248 & Settling $N_{\mathrm{d}}=100$ & UM & 30 & 100 & 30 & PD \\
\hline u-bi250 & Settling $N_{\mathrm{d}}=300$ & UM & 30 & 300 & 30 & PD \\
\hline u-bi283 & Radiative transfer $N_{\mathrm{d}}=100$ & UM & 100 & 30 & 30 & PD \\
\hline u-bi282 & Radiative transfer $N_{\mathrm{d}}=300$ & UM & 300 & 30 & 30 & PD \\
\hline
\end{tabular}

and simulations (Fig. 2); 9 bins are used to span WVP (0$\left.40 \mathrm{~kg} \mathrm{~m}^{-2}\right)$, and 10 are used for SST (275-305 K). We propose that a multiple-linear-regression model of the form,

$$
\begin{aligned}
\mathrm{LWP}= & a_{\mathrm{ccn}} \mathrm{CCN}+a_{2} \omega_{550}+a_{3} \mathrm{EIS}+a_{4} \mathrm{WVP}+a_{5} \mathrm{SST} \\
& +a_{6} \mathrm{SHF}+a_{7},
\end{aligned}
$$

be trained in each bin of SST and WVP. All the predictors within the regression model are environmental drivers that are external to the clouds being influenced. However, robust remote-sensing observations of $\mathrm{CCN}$ are lacking and $\ln \left(N_{\mathrm{d}}\right)$ is used in its place. As discussed above, $N_{\mathrm{d}}$ is predominantly a function of $\mathrm{CCN}$ availability. Thus, a multiplelinear-regression model,

$$
\begin{aligned}
\mathrm{LWP}= & a_{1} \ln \left(N_{\mathrm{d}}\right)+a_{2} \omega_{550}+a_{3} \mathrm{EIS}+a_{4} \mathrm{WVP}+a_{5} \mathrm{SST} \\
& +a_{6} \mathrm{SHF}+a_{7},
\end{aligned}
$$

is trained in each bin of WVP and SST. Bins that contain fewer than 3000 data points are excluded. (Units of LWP are in $\mathrm{g} \mathrm{m}^{-2}, N_{\mathrm{d}}$ is in $\mathrm{cm}^{-3}$, subsidence is in $\mathrm{Pas}^{-1}$, EIS is in $\mathrm{K}, \mathrm{WVP}$ is in $\mathrm{kg} \mathrm{m}^{-2}$, SST is in $\mathrm{K}$, and SHF is in $\mathrm{W} \mathrm{m}^{-2}$.) A $99 \%$ confidence interval is used to determine if a coefficient is significant (different from zero). The initiation of precipitation in boundary-layer cloud can substantially impact LWP within a given cloud with a timescale longer than the daily sampling timescale utilized here (Berner et al., 2013). However, the spatial scale of our analysis $\left(1^{\circ} \times 1^{\circ}\right)$ samples clouds at many stages of their life cycle. This means that we do not need to consider rain to be a predictor of LWP and may think of it as scaling with cloud LWP.

Training the regression model in Eq. (4) produces a measure of the covariance between predictors and predictands. (a) LWP MAC-LWP $\left[\mathrm{g} \mathrm{m}^{-2}\right]$

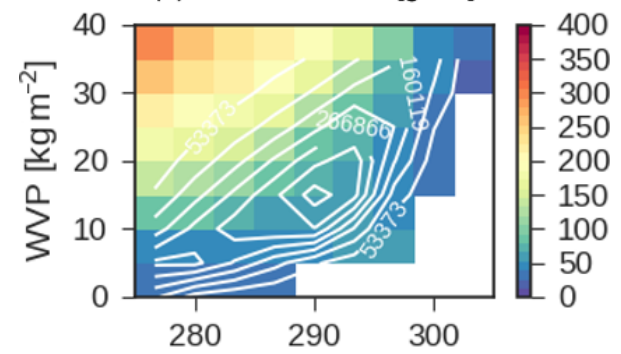

(b) LWP UM $\left[\mathrm{g} \mathrm{m}^{-2}\right]$

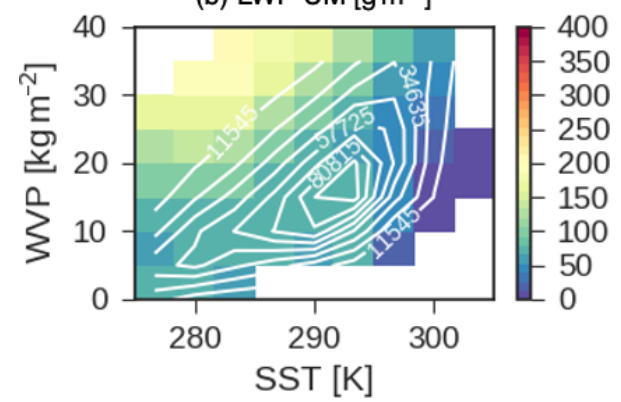

Figure 2. MAC-LWP-observed (a) and UM-simulated (b) LWP in the space of SST and WVP in the region $30-60^{\circ} \mathrm{N}$. White lines show the distribution of data in SST-WVP space. The contours of number of observations in each bin are shown in white.

In particular, it produces a measure of the covariability between $\ln \left(N_{\mathrm{d}}\right)$ and LWP $\left(a_{1}\right)$. However, this covariance does not show causality. $N_{\mathrm{d}}$ may enhance LWP by, for instance, suppressing rain (Albrecht, 1989), and it is this relationship where causality runs from $N_{\mathrm{d}}$ to LWP that is of interest in understanding adjustments. However, the observed covariabil- 


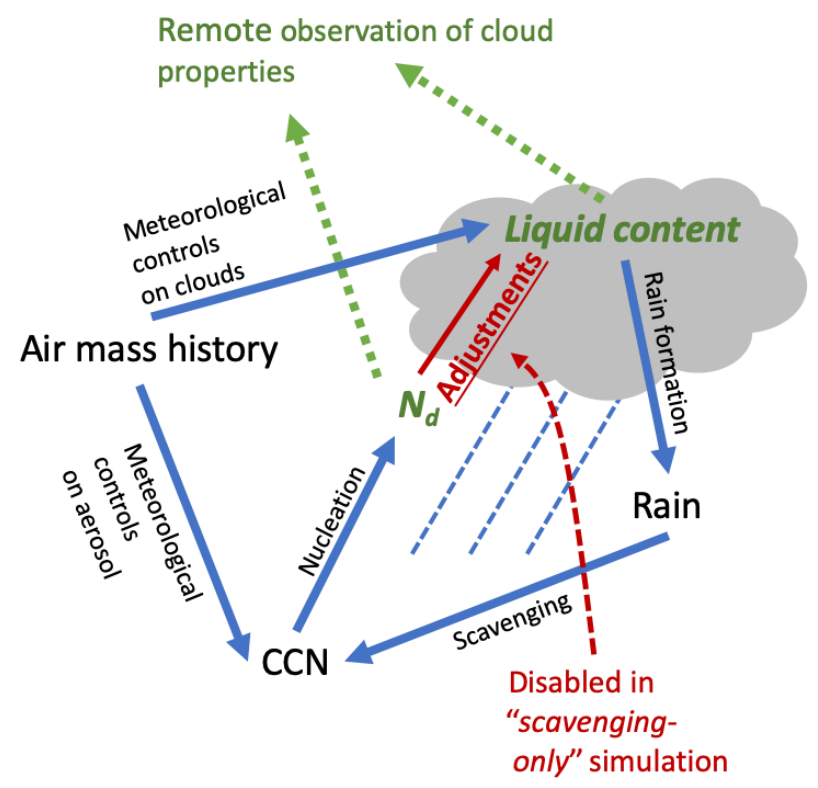

Figure 3. A schematic illustration of the mechanisms linking cloud, aerosol, and meteorology considered in this study. Observed quantities are shown in green (in this case $N_{\mathrm{d}}$ and LWP). Adjustments (shown in red) are the causal link that flow from $N_{\mathrm{d}}$ to LWP, and inferring them is the focus of this study. In the "scavenging-only" simulation the $N_{\mathrm{d}}$ seen by the cloud physics is set to a constant value.

ity between $N_{\mathrm{d}}$ and LWP is also the product of causality running from LWP to $N_{\mathrm{d}}$ due to precipitation removing aerosol and reducing $N_{\mathrm{d}}$ (Wood et al., 2012). The overall covariance between $N_{\mathrm{d}}$ and LWP is the product of these two causal pathways as well as correlation induced by environmental factors driving both clouds and aerosol and by geographic and seasonal distribution of sources of aerosol relative to cloud. Figure 3 shows a schematic of these causal flows.

How do we constrain adjustments based on examination of modeled and observed $N_{\mathrm{d}}$ and LWP if we cannot disentangle causality? The solution we propose is to use a simplified version of the model to characterize the sensitivity of $N_{\mathrm{d}}$ to precipitation and other factors and use this sensitivity to interpret the full model. To conceptualize why this process can estimate the sensitivity of LWP to $N_{\mathrm{d}}$ we can write an equation describing small changes in LWP in the space of small changes in $N_{\mathrm{d}}$. First, we consider that $N_{\mathrm{d}}$ acting on cloud microphysics $\left(N_{\mathrm{d}_{\text {Cloud }}}\right)$ and $N_{\mathrm{d}}$ when precipitation scavenging is the only causal factor linking cloudiness and $N_{\mathrm{d}}\left(N_{\mathrm{d}_{\text {Scav }}}\right)$ as separate entities. In the latter case air mass history and sinks unrelated to precipitation can affect $N_{\mathrm{d}}$, in addition to the effect of precipitation scavenging, but precipitation scavenging is the only causal link between cloud and aerosol (see Fig. 3). We consider changes in LWP relative to $N_{\mathrm{d}_{\text {Cloud }}}$ and $N_{\mathrm{dScav}_{\text {sca }}}$. That is to say we consider $\mathrm{LWP}=f n\left(\ln \left(N_{\mathrm{d}_{\text {Cloud }}}\right), \ln \left(N_{\mathrm{dScav}_{\text {sav }}}\right)\right)$, where the logs are added
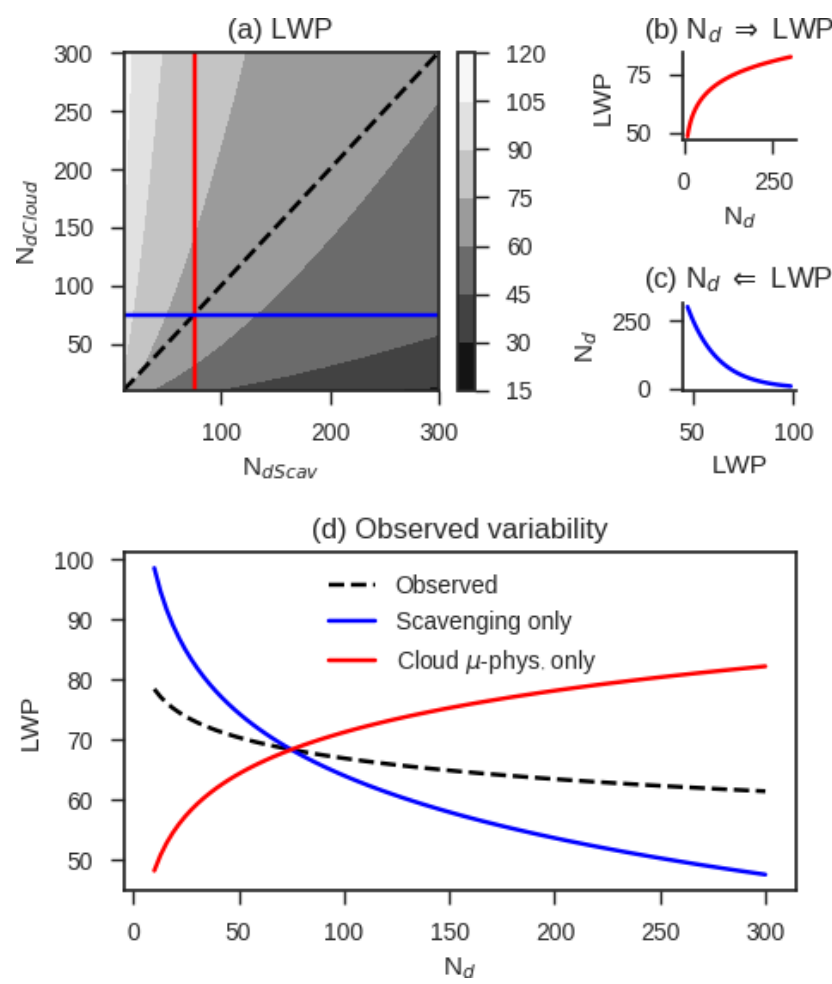

Figure 4. A simple conceptual model demonstrating how variance due to precipitation driving of $N_{\mathrm{d}}$ and due to $N_{\mathrm{d}}$ driving changes in LWP through cloud microphysics affects total covariance between $N_{\mathrm{d}}$ and LWP in observations and models. $N_{\mathrm{d}}$ where scavenging is the only causal link between cloud and aerosol $\left(N_{\mathrm{dScav}}\right)$ and $N_{\mathrm{d}}$ affecting the cloud microphysics $\left(N_{\mathrm{dCloud}}\right)$ are considered to be distinct entities. The contour map in (a) illustrates a potential topological LWP space in terms of $N_{\mathrm{dCloud}}$ and $N_{\mathrm{dScav}}$. The case where $N_{\mathrm{dCloud}}$ is set to a constant value is shown with a blue line, and the case where $N_{\mathrm{dCloud}}$ is increased independently is shown with a red line. In a causal sense this implies $N_{\mathrm{dCloud}}$ driving LWP (shown in b) and $N_{\mathrm{dScav}}$ being driven by LWP (shown in $\mathbf{c}$ ), where $N_{\mathrm{dScav}}$ is negatively correlated with LWP because $\mathrm{d} N_{\mathrm{dScav}} / \mathrm{d} R<0$ and $\mathrm{dLWP} / \mathrm{d} R>0$, where $R$ is rain rate. The observed variability in LWP in terms of $N_{\mathrm{d}}$ is shown in (d) for the cases $N_{\mathrm{dCloud}}=N_{\mathrm{d}}$ and $N_{\mathrm{dScav}}=$ constant (red), $N_{\mathrm{dScav}}=N_{\mathrm{d}}$ and $N_{\mathrm{dCloud}}=$ constant (blue), and $N_{\mathrm{dCloud}}=N_{\mathrm{dScav}}=N_{\mathrm{d}}$ (the real world; dashed line).

for consistency with Eq. (4) and all other terms in Eq. (1) are held fixed and the first term is expanded.

Conceptually, LWP is increased with increasing $N_{\mathrm{d}_{\text {Cloud }}}$ (Fig. $4 \mathrm{~b}$ ), and $N_{\mathrm{d}_{\text {Scav }}}$ is reduced by increasing rain rates, which increase with LWP (Fig. 4c). In the topographic space describing LWP in terms of $N_{\mathrm{d}_{\text {Cloud }}}$ and $N_{\mathrm{d} \text { Scav }}$, reduced $N_{\mathrm{d}_{\text {Scav }}}$ corresponds to increased precipitation rates and, in turn, LWP. That is to say,

$\frac{\mathrm{d} N_{\mathrm{dScav}}}{\mathrm{d} R}<0, \quad \frac{\mathrm{d} R}{\mathrm{dLWP}}>0$, 
where $R$ is the rain rate, so the reciprocal of the product of these terms gives

$$
\frac{\mathrm{dLWP}}{\mathrm{d} N_{\mathrm{dScav}}}<0 \text {. }
$$

Thus, a small change in LWP in terms of changes in these two variables alone is

$$
\begin{aligned}
\mathrm{dLWP}= & \frac{\partial \mathrm{LWP}}{\partial \ln \left(N_{\mathrm{d}_{\text {Scav }}}\right)} \mathrm{d} \ln \left(N_{\mathrm{d}_{\text {Scav }}}\right) \\
& +\frac{\partial \mathrm{LWP}}{\partial \ln \left(N_{\mathrm{d}_{\text {Cloud }}}\right)} \mathrm{d} \ln \left(N_{\mathrm{d}_{\text {Cloud }}}\right) .
\end{aligned}
$$

We assume that scavenging is unaffected by changes in $N_{\mathrm{d}_{\text {Cloud }}}$ affecting rain rates, so there are no higher-order terms, although this may not be the case in reality (Wood et al., 2012), and this feedback is found to substantially enhance the strength of adjustments in some models (Jing and Suzuki, 2018). A visualization of Eq. (7) is shown in Fig. 4a. The best fit of LWP to $N_{\mathrm{d}}$ gives the sum of the partial derivatives of the two terms

$$
\begin{aligned}
\frac{\mathrm{dLWP}}{\mathrm{d} \ln \left(N_{\mathrm{d}}\right)}= & \left(\frac{\partial \mathrm{LWP}}{\partial \ln \left(N_{\mathrm{d}_{\text {Scav }}}\right)}\right)_{N_{\mathrm{dCloud}}} \frac{\mathrm{d} \ln \left(N_{\mathrm{d}_{\text {Scav }}}\right)}{\mathrm{d} \ln \left(N_{\mathrm{d}}\right)} \\
& +\left(\frac{\partial \mathrm{LWP}}{\partial \ln \left(N_{\mathrm{d}_{\text {Cloud }}}\right)}\right)_{N_{\mathrm{dScav}}} \frac{\mathrm{d} \ln \left(N_{\mathrm{d}_{\text {Cloud }}}\right)}{\mathrm{d} \ln \left(N_{\mathrm{d}}\right)},
\end{aligned}
$$

where subscripts on the partial derivatives indicate that they are evaluated while holding that variable constant. In the control simulation, $N_{\mathrm{d}}=N_{\mathrm{d}_{\text {Cloud }}}=N_{\mathrm{d}_{\text {Scav }}}$ because $N_{\mathrm{dCloud}}$ and $N_{\mathrm{dScav}}$ are not distinct entities. That is to say, the cloud microphysics and radiation see that the $N_{\mathrm{d}}$ calculated by the nucleation scheme and aerosol experiences the effects of scavenging and meteorology. In this particular case the derivatives of $N_{\mathrm{d}_{\text {Scav }}}$ and $N_{\mathrm{d}_{\text {Cloud }}}$ each go to unity because the $N_{\mathrm{d}}$ seen by the cloud and affected by scavenging is equal, and we are left with

$$
\frac{\mathrm{dLWP}}{\mathrm{d} \ln \left(N_{\mathrm{d}}\right)}=\left(\frac{\partial \mathrm{LWP}}{\partial \ln \left(N_{\mathrm{d}_{\mathrm{Scav}}}\right)}\right)_{N_{\mathrm{d}_{\text {Cloud }}}}+\left(\frac{\partial \mathrm{LWP}}{\partial \ln \left(N_{\mathrm{d}_{\text {Cloud }}}\right)}\right)_{N_{\mathrm{d}_{\text {Scav }}}} .
$$

We always sample along the dashed line in Fig. 4a in the observational record or in a model where clouds are sensitive to $N_{\mathrm{d}}$ and aerosol is scavenged, giving the curve in Fig. 4d. This curve combines the effects of causality flowing from $N_{\mathrm{d}}$ to LWP and from LWP to precipitation to aerosol and onto $N_{\mathrm{d}}$. The term $\frac{\partial \text { LWP }}{\partial \ln \left(N_{\mathrm{d}_{\text {Cloud }}}\right)}$ is the key to constraining adjustments because it describes the sensitivity of LWP to changes in $N_{\mathrm{d}}$ (in this analogy the slope of LWP along the red line in Fig. 4a). While we cannot disentangle causality in observations or in a model where $N_{\mathrm{d}}$ affects cloud microphysics, we propose that in a model configuration where cloud microphysics (e.g., radiation, settling, and autoconversion in UM GA7.1) are unaffected by $N_{\mathrm{d}}$ we may estimate the term $\frac{\partial \mathrm{LWP}}{\partial \ln \left(N_{\mathrm{d}}{ }_{\text {Scav }}\right)}$. That is to say, if $N_{\mathrm{d}_{\text {Cloud }}}=$ constant and $N_{\mathrm{d}}=N_{\mathrm{d} \text { sav }}$, then

$$
\frac{d \mathrm{LWP}}{d \ln \left(N_{\mathrm{d}}\right)}=\left(\frac{\partial \mathrm{LWP}}{\partial \ln \left(N_{\mathrm{d}_{\mathrm{Scav}}}\right)}\right)_{N_{\mathrm{d}_{\mathrm{Cloud}}}}
$$

and the best fit of LWP to $N_{\mathrm{d}}$ in the scavenging-only simulation is just a measure of the scavenging of aerosol by precipitation and the non-causal covariance between $N_{\mathrm{d}}$ and LWP induced by other confounding factors.

Thus, the sensitivity $\frac{\partial \mathrm{LWP}}{\partial \ln \left(N_{\mathrm{d}_{\mathrm{Cl}} \text { oud }}\right)}$ can be estimated as the difference between the regression of LWP on $N_{\mathrm{d}}$ trained in a simulation where clouds are insensitive to $N_{\mathrm{d}}\left(N_{\mathrm{d}_{\text {Cloud }}}=\right.$ constant; scavenging only) and the regression in a control simulation $\left(N_{\mathrm{d}}=N_{\mathrm{d}_{\text {Cloud }}}=N_{\mathrm{d}_{\text {Scav }}}\right)$ because

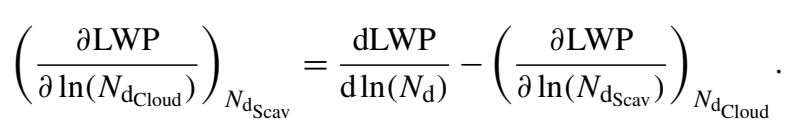

We will use this correction for variability induced by factors besides adjustments throughout the paper to infer the effects of $N_{\mathrm{d}}$ on cloud properties in model configurations and the observations. We note that this methodology is subject to several limitations. First, as noted above, it assumes that feedbacks between adjustments and scavenging are small. This assumption will break down as adjustments become stronger. However, the response in cloud to transient changes in aerosol does not appear to permit very strong adjustments (Malavelle et al., 2017; Toll et al., 2017, 2019). Second, it is assumed here that the relationship between LWP and $\ln \left(N_{\mathrm{d}}\right)$ is linear. Empirically this assumption appears to hold in the models and observations (as shown in the following section), and inclusion of higher-order polynomials of $\ln \left(N_{\mathrm{d}}\right)$ in Eq. (3) did not alter our results.

To reiterate, non-causal factors also lead to correlation between $N_{\mathrm{d}}$ and LWP because air mass history is important for both clouds and aerosol (Mauger and Norris, 2007). In the discussion of the conceptual model presented above we focused on the impact of changes in $N_{\mathrm{d}}$ on LWP and vice versa. Spurious correlation due to air mass history will affect both terms on the right-hand side of Eq. (11) when they are calculated using regression. Thus, the correction for scavenginginduced variability in Eq. (11) also corrects for variability induced by air mass history simultaneously affecting $N_{\mathrm{d}}$ and LWP.

\section{Results}

\subsection{Variance in LWP as a function of $N_{\mathrm{d}}$}

As described in the Methods section, data from observations and the control simulation in the UM between 30 and $60^{\circ} \mathrm{N}$ over oceans and $2000 \mathrm{~km}$ from cyclone centers at a daily 
mean resolution are binned by WVP and SST, and the regression model shown in Eq. (4) is trained in each bin. If we plot the quantity,

$$
\mathrm{LWP}-a_{2} \omega_{500}-a_{3} \mathrm{EIS}-a_{4} \mathrm{WVP}-a_{5} \mathrm{SST}-a_{6} \mathrm{SHF}-a_{7},
$$

as a function of $N_{\mathrm{d}}$ we can see that the coefficient relating LWP to $N_{\mathrm{d}}$ is greater than zero at $99 \%$ confidence, once variability associated with meteorological predictors is removed (Fig. 5). The residual variance in LWP covaries with $N_{\mathrm{d}}$ similarly between the observations and UM simulations where observations exist. However, one key difference is the span of $N_{\mathrm{d}}$ values in the observations and simulations. Observed $N_{\mathrm{d}}$ almost never falls below $30 \mathrm{~cm}^{-3}$ (the grey line in Fig. 5), while the $N_{\mathrm{d}}$ calculated by the model occasionally falls below this value $\left(\sim 10 \%\right.$ of modeled $\left.\ln \left(N_{\mathrm{d}}\right)\right)$. This is not surprising because the model suffers from no retrieval limitations and can always measure an $N_{\mathrm{d}}$, even when cloud is extremely tenuous. Ultimately the goal of this study is to utilize the slope of LWP with respect to $N_{\mathrm{d}}$ to infer adjustment strength. However, using the slope from the observations and the models will produce quite different values due to the strong increase in LWP with $N_{\mathrm{d}}$ below $30 \mathrm{~cm}^{-3}$. In order to compare observations and models fairly we exclude data for $N_{\mathrm{d}}<30 \mathrm{~cm}^{-3}$.

For $N_{\mathrm{d}}>30 \mathrm{~cm}^{-3}$ residual LWP decreases with increasing $N_{\mathrm{d}}$ in both observations and models. This agrees with the notion that precipitation variability drives $N_{\mathrm{d}}$ (Wood et al., 2012) and agrees with previous analysis (Gryspeerdt et al., 2019). Clearly, this does not mean that the model reduces cloudiness in response to aerosol. The cloud microphysics within the UM GA7.1 must increase LWP in response to a change in $N_{\mathrm{d}}$, and analysis of the model response to changes from preindustrial (PI) to present-day (PD) aerosol confirmed a negative forcing from adjustments (Mulcahy et al., 2018). As discussed in the Methods section, the difference in slopes between the scavenging-only and control simulation is a proxy for the response in cloud microphysics to $N_{\mathrm{d}}$. Before analyzing this difference, we will briefly discuss the covariance between LWP and meteorological predictors in the observations and the control simulations.

\subsection{Covariances between LWP and meteorology}

Before returning to discussing aerosol-cloud adjustments, we discuss the covariances between observed LWP and the other predictors in Eq. (4). This is shown in Fig. 6. The explained variance $\left(R^{2}\right)$ by the regression model exceeds $40 \%$ except at low WVP and SST. The variance explained across all bins of SST and WVP is $46 \%$ of daily mean $1^{\circ} \times 1^{\circ}$ variability. That is to say, nearly half of the day-to-day variability in LWP across the midlatitudes away from cyclones can be explained as a simple linear combination of five variables.

Several of the predictors have uniform effects on LWP: LWP decreases with subsidence (consistent with Myers and Norris, 2013), increases with WVP, decreases with increas- ing SST (consistent with Qu et al., 2015, and references therein), and increases with sensible heat flux (consistent with Miyamoto et al., 2018). We note that at very low SST it appears that LWP may increase with SST. It is possible that this feature is related to ice-to-liquid transitions (McCoy et al., 2015b, 2016; Tsushima et al., 2006; Senior and Mitchell, 1993; Tan et al., 2016), but this region only accounts for a small fraction of the overall data volume. The only meteorological predictor that correlates positively and negatively with LWP across the SST-WVP phase space is EIS. At higher WVP and lower SST, EIS and LWP are negatively correlated, while at low WVP and high SST, they are positively correlated. The latter effect is consistent with increasing EIS increasing the cloud fraction (Wood and Bretherton, 2006). One possibility is that because clouds are closer to $100 \%$ in areal coverage at higher WVP and lower SST, increasing stability suppresses the thickening of cloud in this regime, while the clouds cannot expand horizontally.

Examination of the control simulation shows very similar covariances between meteorological predictors and LWP (Fig. 7). Notable differences are the stronger positive covariance between SST and LWP at low SST and uniform negative covariance between EIS and LWP across the SST-WVP phase space. However, the relationship between LWP and meteorology is strikingly similar to that between observations and the UM. The explained variance by predictors tends to be higher in the UM GA7.1 (64\%), but it is hard to say how much of this difference in explained variance is due to simplification of the real atmosphere and cloud physics by the model and how much is due to observational error.

In this framework we also characterize the covariance between $\ln \left(N_{\mathrm{d}}\right)$ and LWP. The correlation between $\ln \left(N_{\mathrm{d}}\right)$ and LWP is primarily negative in the observations, with positive correlations only occurring at high WVP and low SST. The correlation between LWP and $\ln \left(N_{\mathrm{d}}\right)$ in the model is almost uniformly negative (in the data set restricted to $N_{\mathrm{d}}>$ $30 \mathrm{~cm}^{-3}$ ). Standardization of the predictor strength estimates the effect of a standard deviation change in each predictor in standard deviations of LWP. In both the observations and models the impact of a standard deviation in meteorological predictors dwarfs the effect of a standard deviation in $\ln \left(N_{\mathrm{d}}\right)$, with contributions from subsidence and SHF dominating variability. That is to say, the relative contributions of variability in $N_{\mathrm{d}}$ are quite small in comparison to variability that is simply due to the weather.

\subsection{Inferring the effect of $N_{\mathrm{d}}$ on LWP}

As we have seen, the correlation between LWP and $N_{\mathrm{d}}$ is mostly negative. The slope relating $\ln \left(N_{\mathrm{d}}\right)$ to LWP in the context of Eq. (4) is reproduced in Fig. 8a and b. However, if we manually set the $N_{\mathrm{d}}$ seen by autoconversion, radiation, and settling to $75 \mathrm{~cm}^{-3}$ in the UM GA7.1 (the approximate mean value in the study region) the negative covariance strengthens substantially (Fig. 8c). This model version is termed "scav- 


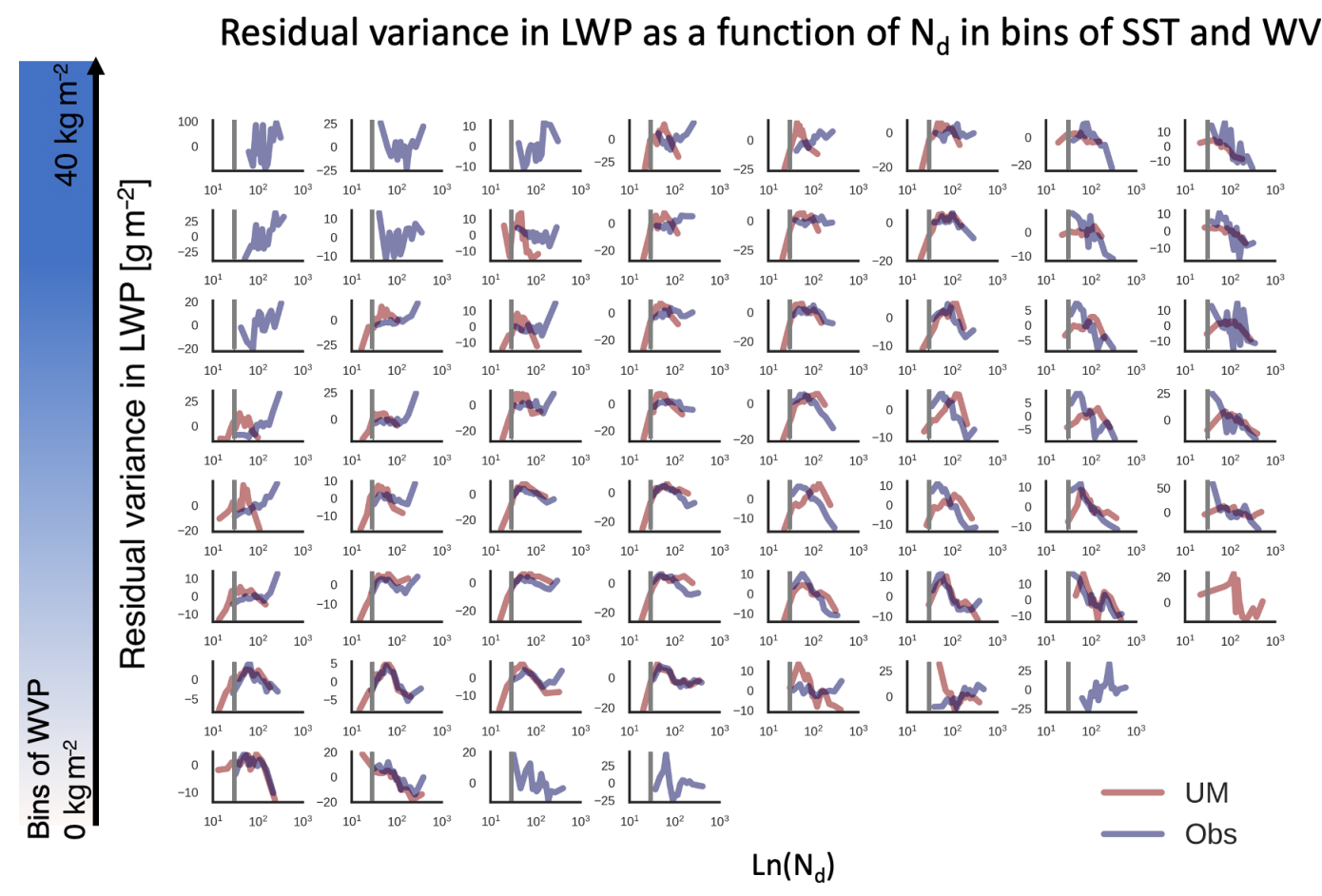

$275 \mathrm{~K}$

Bins of SST

Figure 5. Residual variance in LWP after removing variability associated with other predictors (Eq. 12) plotted as a function of $N_{\mathrm{d}}$ in the UM GA7.1 and observations (Obs.). Each subplot corresponds to a bin of WVP and SST. Due to retrieval limitations, values of $N_{\mathrm{d}}$ below $30 \mathrm{~cm}^{-3}$ (grey line) are almost never observed but occur in model output.
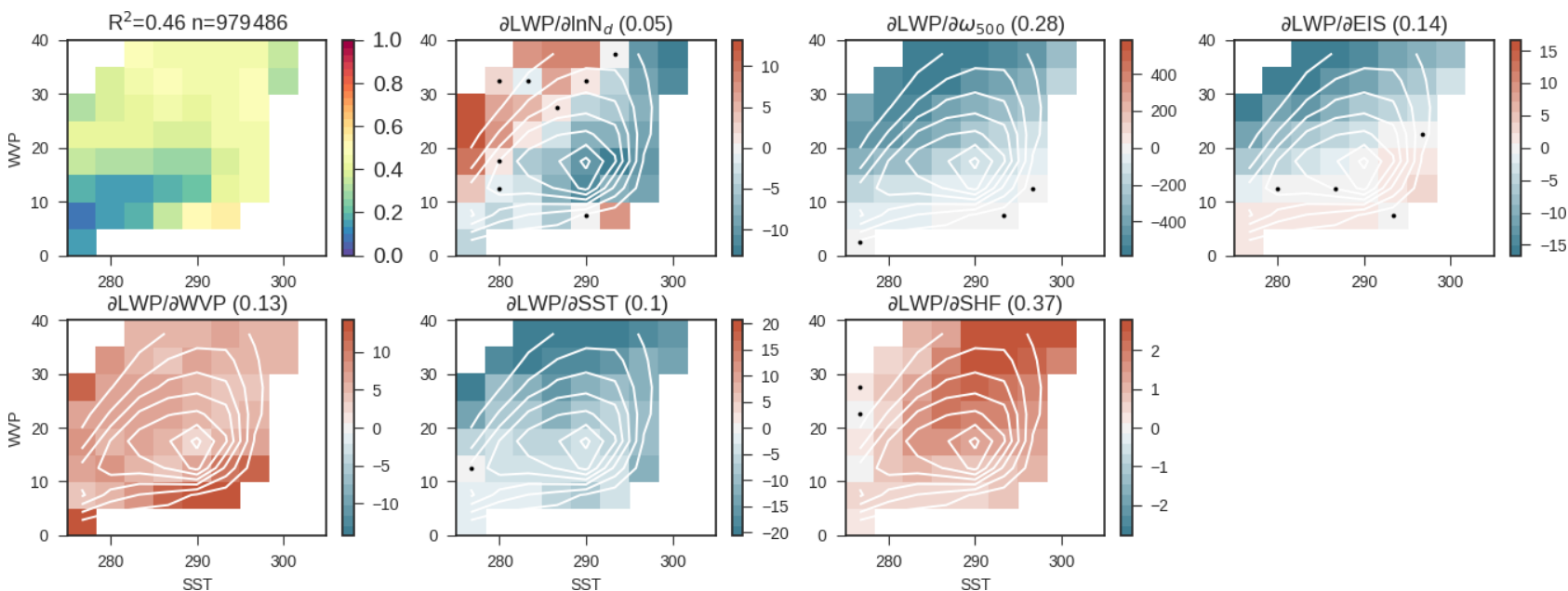

Figure 6. The regression coefficients relating observed LWP to predictors in the phase space of SST and WVP. Regression coefficients not significant at $99 \%$ confidence are marked with a dot. White contours show the distribution of observations in the WVP-SST phase space. The first plot shows the explained variance in each bin. The explained variance within the entire data set is noted in the title along with the number of observations. The remaining plots show the coefficients relating each predictor to LWP. In the title the weighted mean of the absolute value of the standardized coefficient ( $|\partial \sigma \mathrm{LWP} / \partial \sigma x|)$ is shown in brackets to give an estimate of contribution of each predictor to the variance. Regression coefficients are as described in Eq. (4). 

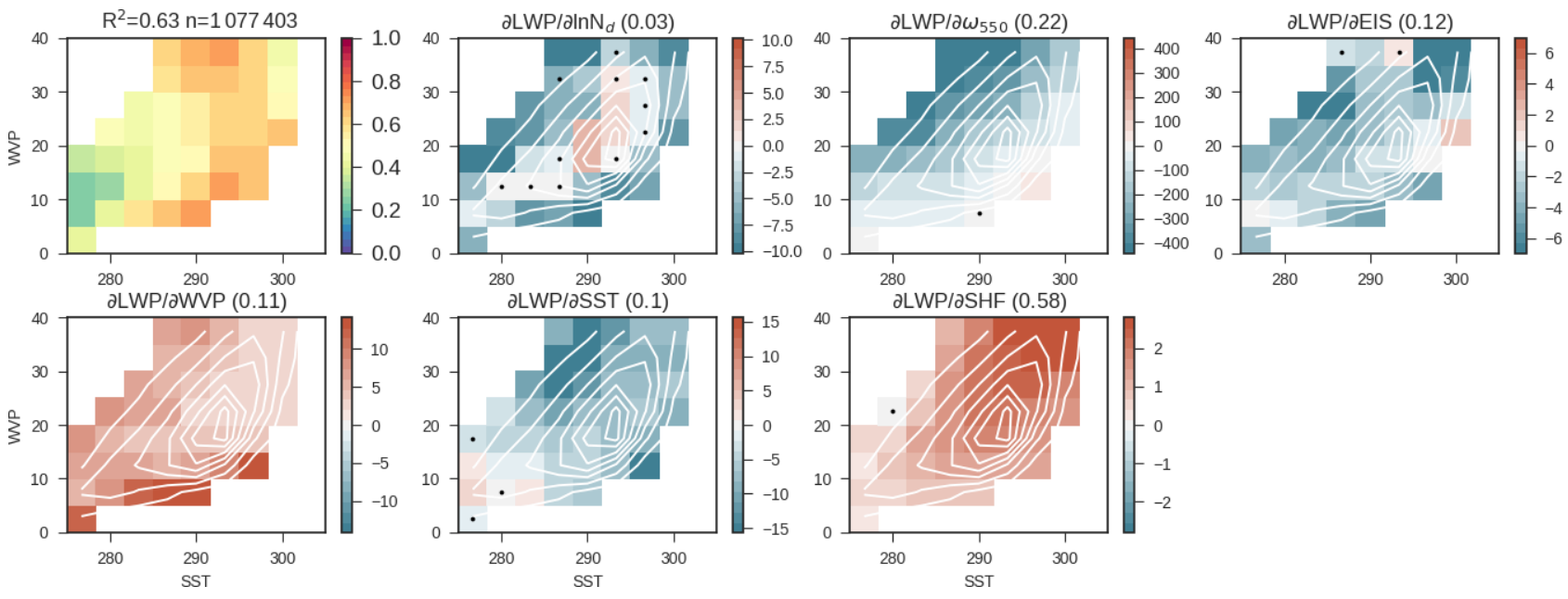

Figure 7. As in Fig. 6 but showing the covariance within the UM.

enging only" because scavenging is the only causal link between cloud and aerosol (Fig. 3). As discussed in the Methods section, the effect of changes in $N_{\mathrm{d}}$ on LWP may be approximated by the difference between Fig. $8 \mathrm{~b}$ and c. This is shown in Fig. 8e. This agrees with our expectation based on our knowledge of how the UM GA7.1 treats liquid cloud processes. We know that the effect of increasing $N_{\mathrm{d}}$ on autoconversion and settling is to inhibit the conversion of cloud to rain and reduce cloud droplet fall speed.

To evaluate the accuracy of this method in inferring the sensitivity of LWP to $N_{\mathrm{d}}$ we conduct simulations where causality is forced to flow from the $N_{\mathrm{d}}$ to LWP. This is done by setting the $N_{\mathrm{d}}$ seen by the autoconversion, settling, and radiation to constant values. Two simulations are conducted for each mechanism, with $N_{\mathrm{d}}$ set to 100 and $300 \mathrm{~cm}^{-3}$. The $N_{\mathrm{d}}$ seen by the other mechanisms is held constant at $30 \mathrm{~cm}^{-3}$. A further three simulations are conducted, in which $N_{\mathrm{d}}$ seen by all three mechanisms is set to 30,100 , and $300 \mathrm{~cm}^{-3}$ (Table 2). This yields a set of simulations describing the effects on LWP of an increase in $N_{\mathrm{d}}$ in the autoconversion, settling, or radiation as well as via all three mechanisms simultaneously. Analysis of the effects of increased $N_{\mathrm{d}}$ seen by the radiation code showed negligible changes in LWP and is not shown here.

As in Fig. 7, the fit in Eq. (4) is trained in each bin of WVP and SST across each set of three simulations. The $N_{\mathrm{d}}$ seen by the model parameterization is used in the multiple linear regression (Eq. 4). As expected, given the functional form of these parameterizations (Eqs. 1 and 2) the effect of increasing $N_{\mathrm{d}}$ in either autoconversion or settling results in an increase in LWP, as does the case where $N_{\mathrm{d}}$ in the settling, autoconversion, and radiation are all varied together. The effect of a perturbation in the $N_{\mathrm{d}}$ seen by autoconversion, radiation, and settling on LWP is nearly identical to the slope inferred by subtracting the slope in the scavenging-only run from the control run following Eq. (11) (Fig. 8f). This comparison be- tween the true model sensitivity of LWP to changes in $N_{\mathrm{d}}$ supports the validity of the multiple-linear-regression-based inference approach pursued here.

Autoconversion and settling are likely to interact with each other in a non-linear manner. As one is suppressed as a sink of cloud liquid, the other will grow (for example, if the conversion of cloud to rain is rendered inefficient, then the gravitational settling of cloud droplets will become more efficient as the liquid content grows). Analysis of crosstalk between these terms is not the focus of this article, but sensitivity of LWP to changes in each mechanism is shown in Fig. 8f. The effect of perturbing settling $N_{\mathrm{d}}$ on LWP is larger than the effect of perturbing the autoconversion $N_{\mathrm{d}}$, singling it out as an important lever in controlling adjustment strength for future study. This result is consistent with the large process rate for settling relative to autoconversion found in weakly precipitating low-cloud regimes in CAM5 (Gettelman et al., 2013). It is also possible that interactions between settling and $N_{\mathrm{d}}$ may decrease the sensitivity of warm rain to autoconversion representation that is diagnosed in other models (Michibata et al., 2019; Jing et al., 2019). Overall, the results of this study are insensitive to whether settling or autoconversion has a stronger effect on aerosol-cloud adjustments because we assume that feedbacks between scavenging and adjustments are small.

Given that the scavenging-only simulation can be used to infer the adjustment strength in the UM, we also attempt to use the scavenging-only simulation to infer the strength of adjustments in the real world (Fig. 8d). This assumes that the statistical relationship between LWP and rain rates in the UM GA7.1 and the scavenging of CCN-relevant aerosol by precipitation in the UM GA7.1 is realistic.

Based on the covariance between $N_{\mathrm{d}}$ and LWP in the scavenging-only simulations in the UM GA7.1 and observations we offer an estimate of adjustment strength. The adjustment strength inferred from observations is stronger than the 
(a) Observations $\partial \mathrm{LWP} / \partial \mathrm{ln} \mathrm{N}_{d}$

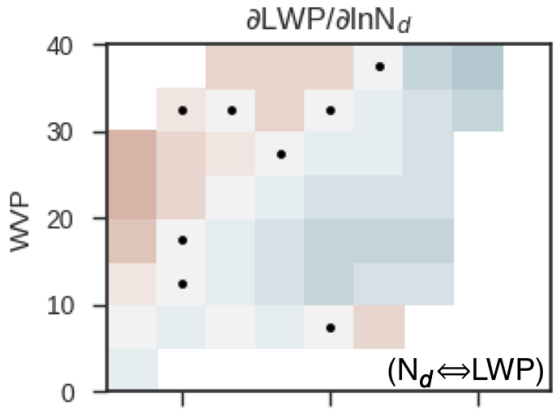

(d) Obs.- scavenging only

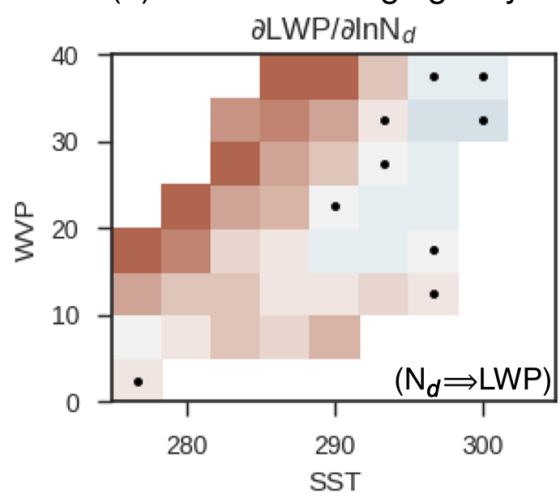

(b) UM

$\partial \mathrm{LWP} / \partial \mathrm{InN} \mathrm{N}_{d}$

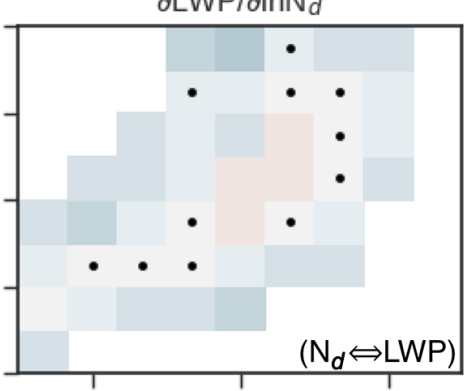

(e) UM - scavenging only $\partial \mathrm{LWP} / \partial \mathrm{InN} \mathrm{N}_{d}$

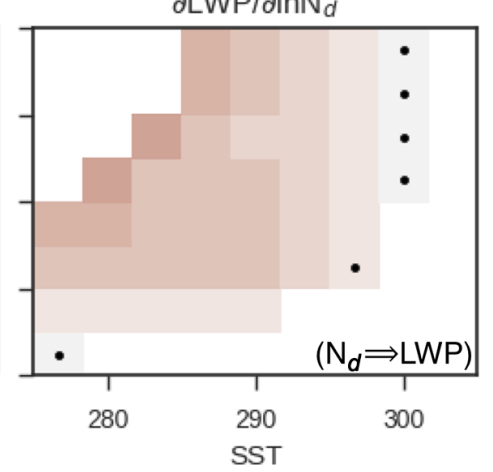

(c) UM scavenging only $\partial \mathrm{LWP} / \partial \mathrm{ln} \mathrm{N}_{d}$

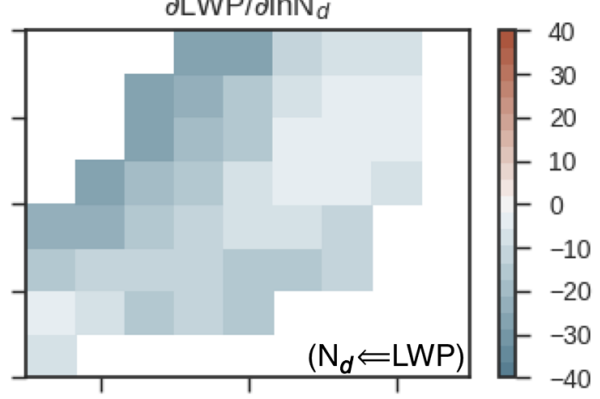

(f) Comparison to fixed $\mathrm{N}_{d}$ simulations

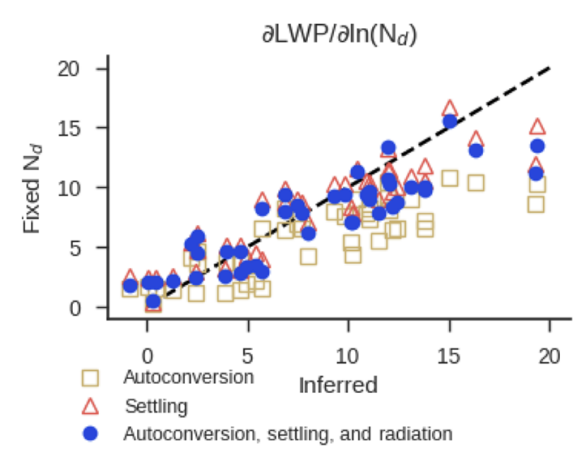

Figure 8. The observed covariance between $N_{\mathrm{d}}$ and LWP and the inferred effect of $N_{\mathrm{d}}$ on LWP. Notations in the bottom right of plots indicate the expected direction of causality. The covariance between $N_{\mathrm{d}}$ and LWP is shown in (a) the observational record (as in Fig. 6) and (b) the control simulation of the UM GA7.1 (as in Fig. 7); (c) a simulation where the $N_{\mathrm{d}}$ seen by the autoconversion, settling, and radiation is set to $75 \mathrm{~cm}^{-3}$ and only scavenging links $N_{\mathrm{d}}$ and LWP. The inferred strength of adjustments in observations (d) calculated as the difference in slope between (a) and (c) as in Eq. (11), and in (e) the UM is calculated as the difference in slope between (b) and (c). Inferred and true adjustment strength for the UM is compared in (f). The inferred adjustment strength in (e) is compared to the sensitivity of LWP to $N_{\mathrm{d}}$ in a set of simulations where $N_{\mathrm{d}}$ is fixed in the autoconversion, settling, and radiation to a range of values, forcing causality to flow from $N_{\mathrm{d}}$ to LWP. The 1:1 line is shown with dashes. Different symbols indicate whether the $N_{\mathrm{d}}$ seen by the autoconversion, settling, or radiation was varied while others were held constant. Each symbol corresponds to a bin in WVP and SST, as in (e).

UM for low SST and high WVP. Unlike the UM, weak negative covariance between LWP and $N_{\mathrm{d}}$ exists for high SST and low WVP. This may indicate that the scavenging of aerosol by the UM is too efficient, or some other confounder of the relationship between LWP and $N_{\mathrm{d}}$ is poorly represented in the model, or it may point to the thinning of cloud via enhanced entrainment (Ackerman et al., 2004), which is not represented in the UM. Overall, the effect of increasing $N_{\mathrm{d}}$ in the UM is an increase in LWP.

We have discussed how to infer adjustment strength from the total covariance between $N_{\mathrm{d}}$ and LWP, which mixes covariance induced by causality flowing from cloud to aerosol and aerosol to cloud. In the next section we show how this inferred adjustment strength from the simple regression model is able to predict LWP adjustments in response to anthropogenic aerosols within the full GCM simulation.

\subsection{Reproducing simulated adjustments between the preindustrial and present-day aerosol emission}

We have produced an estimate of the sensitivity of LWP to changes in $N_{\mathrm{d}}$ in the UM GA7.1 model (Fig. 8e). Does this simple regression model hold skill in reproducing the actual change in LWP within the model between the presentday (PD) and preindustrial (PI) aerosol emissions? Simulations are carried out by setting aerosol emission to preindustrial values. This is done for simulations using the GA7.1 scavenging parameterization. A second set of simulations is conducted where the ECHAM-HAM5 scavenging coefficients are used to estimate the sensitivity to the representation of scavenging. PI, PD, and scavenging-only simulations are conducted for each scavenging configuration.

The change in LWP between the PI and PD ( $\triangle$ LWPPD-PI) simulated by the UM is $2.9 \mathrm{~g} \mathrm{~m}^{-2}$, averaged across the $30-60^{\circ} \mathrm{N}$ region. Using the UM-simulated change in $N_{\mathrm{d}}$ $\left(\Delta N_{\mathrm{dPD}-\mathrm{PI}}\right)$ and the slope relating $\ln \left(N_{\mathrm{d}}\right)$ to LWP diag- 
nosed from present-day variability (Fig. 8) we calculate $\triangle \mathrm{LWP}$ PD-PI. If the covariance between $\ln \left(N_{\mathrm{d}}\right)$ and LWP observed in the control run (Fig. 8b) of the model and $\Delta N_{\mathrm{dPD}-\mathrm{PI}}$ is used to predict $\Delta \mathrm{LWP} \mathrm{PD}-\mathrm{PI}$, the negative correlation introduced by precipitation scavenging leads to a negative $\triangle$ LWP PD-PI (Fig. 9a; in disagreement with the UMsimulated $\triangle \mathrm{LWP} \mathrm{PD}_{\mathrm{PII}}$ ). If the covariance in the scavengingonly simulation (causality flows from clouds to precipitation to aerosol to $N_{\mathrm{d}}$ ) is used (Fig. 8c), the regressionmodel-predicted decrease in LWP between PI and PD aerosol levels doubles. However, if we subtract the sensitivity in scavenging-only simulation from the control simulation to yield the sensitivity of LWP to changes in $N_{\mathrm{d}}$ (Fig. 8e), the $\Delta \mathrm{LWP} \mathrm{PD}_{\mathrm{PI}}$ predicted by the regression model and the UM-simulated $\Delta N_{\mathrm{dPD}-\mathrm{PI}}$ agree well with the UM-simulated $\triangle$ LWP ${ }_{\text {PD-PI }}$ (Fig. 9). This result supports the utility of the inferred sensitivity of LWP to $N_{\mathrm{d}}$ in examining adjustments due to PD aerosol.

What does the covariance between LWP and $\ln \left(N_{\mathrm{d}}\right)$ in the real world tell us about the model? Use of the observational estimate of adjustment strength (Fig. 8d) calculates a $\triangle$ LWP ${ }_{\mathrm{PD}-\mathrm{PI}}$ that is two-thirds of the $\triangle \mathrm{LWP} \mathrm{PD}_{\mathrm{PI}}$ inferred from the control run and $\Delta N_{\mathrm{dPD}-\mathrm{PI}}$ (Fig. 9). This is because, while the inferred sensitivity of LWP to $N_{\mathrm{d}}$ from observations is quite strong in some regions, it is weakly negative in the most commonly occurring WVP-SST regimes (Fig. 8d). That is to say, if the efficacy of precipitation in removing $\mathrm{CCN}$-relevant aerosol in the real atmosphere is near to the efficacy in the UM, the relationship between LWP and rain rates in the real atmosphere is near to the relationship in the $\mathrm{UM}$, and the covariability between $N_{\mathrm{d}}$ and LWP induced by other confounders of the $N_{\mathrm{d}}-\mathrm{LWP}$ relationship is realistic, then the adjustments ( $\triangle \mathrm{LWP} \mathrm{PD}_{\mathrm{PDI}}$ ) simulated by the $\mathrm{UM}$ are not unreasonable, albeit a little large. This result is consistent with constraints provided by simulation of the Holuhraun eruption (Malavelle et al., 2017), which showed that the anomaly predicted by HadGEM3 was within the observed range. However, the observationally inferred sensitivity of LWP to changes in $N_{\mathrm{d}}$ is stronger in low-SST and high-WVP regimes than it is in the UM GA7.1 but much weaker, or even slightly negative, in low-WVP and highSST regimes. This results in a strong latitudinal gradient in $\triangle$ LWP PD-PI between 30 and $60^{\circ} \mathrm{N}$ inferred from observations (Fig. 9b).

The predicted $\triangle \mathrm{LWP} \mathrm{PD}_{\mathrm{PI}}$ based on the control and scavenging-only simulations (Fig. 8e) underestimates the UM-simulated $\triangle \mathrm{LWP}_{\mathrm{PD}-\mathrm{PI}}$ by around $10 \%$. This may result from disregarding feedbacks between precipitation suppression and $N_{\mathrm{d}}$ (Jing and Suzuki, 2018), may simply be due to shortcomings in the simple linear model relating $\ln \left(N_{\mathrm{d}}\right)$ to LWP, or may relate to meteorological differences between the PI and PD simulations not accounted for by meteorological predictors or compositing. However, the fractional reduction in inferred $\triangle \mathrm{LWP} P \mathrm{PD}-\mathrm{PI}$ when observations are used to constrain the sensitivity of LWP to $N_{\mathrm{d}}$ sug- gests that $\triangle \mathrm{LWP} P \mathrm{PD}-\mathrm{PI}$ should be around $60 \%-70 \%$ of the value predicted by the UM GA7.1 averaged across the NH. $\triangle$ LWP $P D-P I$ inferred from observations is extremely dependent on latitude, with almost no change in LWP over lower latitudes and warmer SSTs. We hasten to note that the change in $N_{\mathrm{d}}$ between the PI and PD is uncertain and its prediction by UM GA7.1 may be biased, making the absolute values of the constrained $\triangle \mathrm{LWP} P \mathrm{PD}-\mathrm{PI}$ less relevant than the fractional overestimation in UM-simulated $\triangle \mathrm{LWP} P \mathrm{PD}-\mathrm{PI}$. This analysis is repeated using simulations that are only nudged above level 27 of the model (Fig. S1) and not nudged at all (Fig. S2), with minimal differences from the results presented in the main text.

We have focused on changes in LWP in this work because it is a variable that we have good observations of, it can be compared between models and observations in a straightforward way, and it clearly links to adjustments. However, this variable is not the key variable in discussing radiative forcing and climate sensitivity. How does the radiative forcing from adjustments scale with LWP? Determining the precise effects of adjustments on the shortwave cloud radiative effect is difficult, but if we assume that the perturbations in LWP induced by adjustments are similar to the perturbations that are driven by meteorology, we can offer a simple estimate to inform our understanding of the modeled forcing from adjustments.

Examination of the relationship between LWP and albedo within the UM GA7.1 shows a rapid climb in albedo for low LWP, followed by saturation at higher values, as expected from saturation of the cloud fraction and optical depth (Fig. 10). This curve can be fit by a second-degree polynomial, meaning that the sensitivity of albedo to changes in LWP is a function of the LWP. That is to say, regions where LWP is already high are going to have a smaller increase in albedo for a unit change in LWP. The change in LWP between PI and PD is much smaller than the range of the variation in LWP in the climate mean state, so we use the average of monthly mean LWP between PI and PD to calculate the sensitivity of albedo to changes in LWP for the NH midlatitudes. This sensitivity ( $\alpha / \mathrm{dLWP}$ ) is multiplied by the change in LWP to yield change in albedo. This change in albedo is scaled by the downwelling shortwave to give the change in reflected shortwave.

The change in reflected shortwave predicted from LWP changes in the UM GA7.1 is $1.9-2.0 \mathrm{~W} \mathrm{~m}^{-2}$, depending on the scavenging parametrization used. The change in shortwave inferred from the regression model of LWP trained in the control run and corrected by the scavenging-only run is $1.5 \mathrm{~W} \mathrm{~m}^{-2}$. If the observed sensitivity of LWP to $N_{\mathrm{d}}$ is used to constrain $\triangle \mathrm{LWP}$, the predicted change in reflected shortwave is approximately $1.0 \mathrm{~W} \mathrm{~m}^{-2}$. Thus, we estimate that GA7.1 overpredicts the change in reflected shortwave due to adjustments in response to a given change in $N_{\mathrm{d}}$ by around $50 \%$. This estimate is subject to the caveat that changes in LWP due to adjustments may not affect albedo in the same way as suggested by examining the total variability. For ex- 

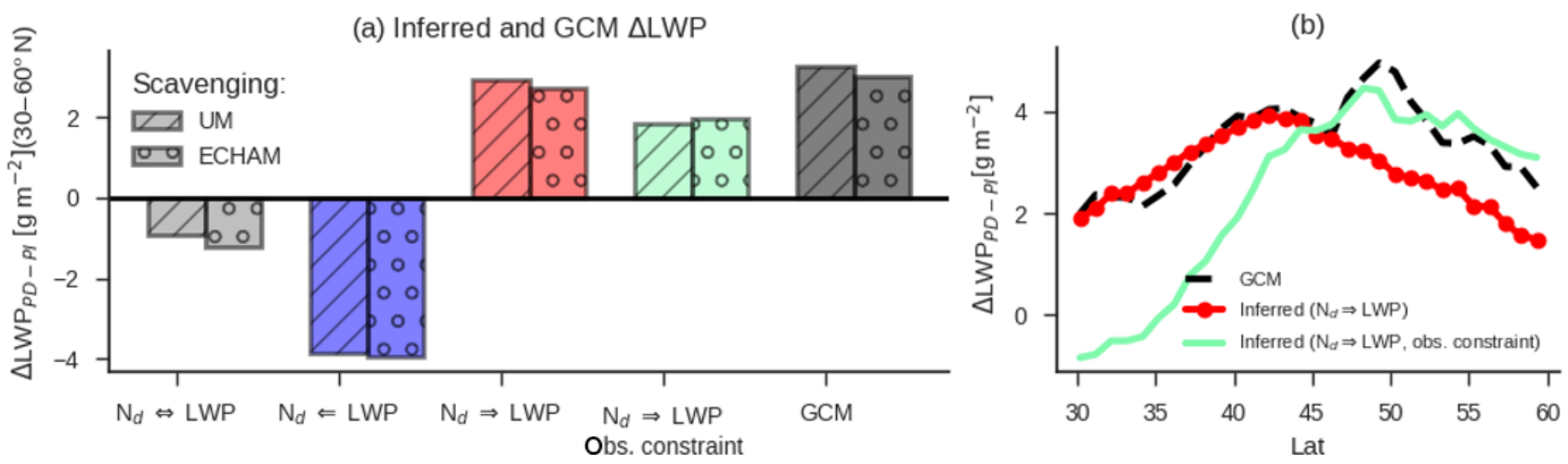

Figure 9. The change in LWP between the simulations with PI and PD aerosol emissions ( $\triangle \mathrm{LWP}$ PD-PI) inferred by covariance between $N_{\mathrm{d}}$ and LWP in the PD and as simulated by the UM. The inferred $\Delta$ LWPPD-PI is calculated using the UM-simulated change in $N_{\mathrm{d}}$. Panel (a) shows the inferred $\triangle \mathrm{LWP}$ PD-PI based on variance in different simulations. The direction of causality is indicated for each case. From left to right: $\triangle$ LWPPD-PI inferred from covariance in the control simulation $\left(N_{\mathrm{d}} \Leftrightarrow \mathrm{LWP}\right.$, causality between $N_{\mathrm{d}}$ and LWP goes both directions; Fig. 8b), inferred from the scavenging-only simulation $\left(N_{\mathrm{d}} \Leftarrow \mathrm{LWP}\right.$, causality from LWP to $N_{\mathrm{d}}$; Fig. 8c), inferred by correcting the total covariance using covariance in the scavenging-only simulation $\left(N_{\mathrm{d}} \Rightarrow \mathrm{LWP}\right.$, causality goes from $N_{\mathrm{d}}$ to LWP Fig. $8 \mathrm{~d}-$ this is the adjustment strength in UM GA7.1 inferred by the method presented in this paper) and when the covariance in observations is combined with the scavenging-only simulation (listed as Obs. constraint). The $\triangle$ LWPPD-PI simulated by the GCM is shown on the right in black. This is the true aerosol-cloud adjustment in the GCM that is compared to the value being inferred in the UM GA7.1, as shown by the red bars. $\triangle$ LWP $P$ D-PI is provided for simulations using the UM GA7.1 scavenging coefficients and ECHAM-HAM5 scavenging coefficients. Panel (b) as in (a) but resolved in latitude and only showing the case when the UM GA7.1 default scavenging is used.

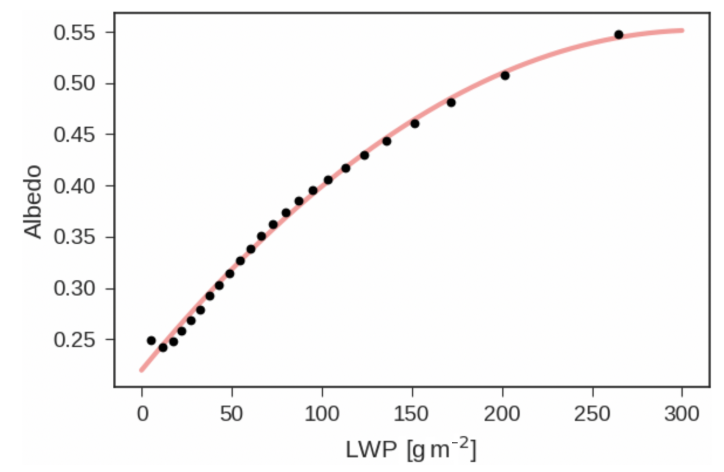

Figure 10. UM GA7.1 daily mean albedo as a function of LWP over ocean between 30 and $60^{\circ} \mathrm{N}$ and outside of cyclones in equal quantiles of LWP (black circles). A second-order polynomial fit is shown using a red line.

ample, adjustments might only increase the liquid content of the thickest clouds and have a relatively slight impact on albedo. However, it is unclear how to provide a more complex calculation than the one presented here.

\section{Discussion}

As the possible range for the radiative forcing from the first indirect effect has narrowed, aerosol-cloud adjustments have become an increasingly central source of uncertainty in aerosol-cloud radiative forcing (Bellouin et al., 2020). Here we focus on the northern midlatitudes, where the majority of anthropogenic aerosol is emitted (Myhre et al., 2013). Previous work has examined aerosol-cloud adjustments in midlatitude cyclones, showing that cyclone liquid water path (LWP) increases with cloud droplet number concentration $\left(N_{\mathrm{d}}\right.$; McCoy et al., 2018b). This work focuses on the remainder of cases in the midlatitudes, when there is no cyclone center within $2000 \mathrm{~km}$ (roughly $42 \%$ of the time between 30 and $60^{\circ}$ N; see Fig. 1).

Untangling the effect of cloud microphysics on cloud macrophysics from the total variability in cloud macrophysics is challenging. In the observational record we can only characterize the covariance between predictors and predictands. In interrogating the observed covariances between cloud properties and different meteorological predictors we find many of the relationships that have been described in the literature documenting cloud-controlling factors (Myers and Norris, 2015). Once meteorological variability is accounted for, statistically significant relationships between cloud microphysics $\left(N_{\mathrm{d}}\right)$ and cloud macrophysics (LWP) appear. In keeping with previous studies (Gryspeerdt et al., 2019), LWP and $N_{\mathrm{d}}$ are found to be negatively correlated. However, this is clearly not consistent with the UM GA7.1 GCM's actual response in LWP to changes in aerosol emissions between PI and PD. This negative correlation is due to a combination of $N_{\mathrm{d}}$ being driven by scavenging, as shown in Wood et al. (2012), and spurious correlation between $N_{\mathrm{d}}$ and LWP driven by external variables affecting both terms (Mauger and Norris, 2007), overwhelming any positive covariance driven by aerosol-cloud adjustments. 
While we cannot disentangle the covariance due to adjustments and covariance due to scavenging and other confounders in the observational record, we can create simulations in which causality is forced to flow from clouds to $N_{\mathrm{d}}$ (scavenging only). Using this measure of non-adjustmentinduced variability in $N_{\mathrm{d}}$, we can infer the effect of changing $N_{\mathrm{d}}$ on LWP. This inferred sensitivity of LWP to $N_{\mathrm{d}}$ agrees well with simulations where $N_{\mathrm{d}}$ is manually varied in the cloud microphysics (Fig. 8f). The inferred sensitivity of LWP to $N_{\mathrm{d}}$, combined with the UM-predicted change in $N_{\mathrm{d}}$, reproduces the UM-predicted change in LWP between the PI and PD ( $\triangle$ LWP PD-PI; Fig. 9). These two tests support this method's relevance to understanding aerosol-cloud adjustments.

The analysis presented here, combined with the enhancement in LWP in cyclone systems shown in McCoy et al. (2018b), points toward an overall increase in LWP across the NH midlatitudes in response to anthropogenic aerosol. Ultimately, while the regimes examined here and in McCoy et al. (2018b) are very different, the detection of a change in LWP in response to changes in $N_{\mathrm{d}}$ rests on the ability of the technique to account for non-adjustmentinduced variability in $N_{\mathrm{d}}$. In McCoy et al. (2018b) this was done by stratifying the data set by the cyclone precipitation rate, which is well-constrained by the large-scale environment (Field and Wood, 2007); this in turn stratifies the data set by the scavenging of aerosol.

Assuming that scavenging in the UM GA7.1 model is realistic, that the relationship between LWP and precipitation is reasonable, and that the non-causal covariance produced by other factors is replicated in the model, we evaluate the strength of adjustments based on observations. This reveals that the present version of the UM GA7.1 overestimates the sensitivity of LWP to changes in $N_{\mathrm{d}}$ by approximately $50 \%$ outside of midlatitude cyclones. Calculation of the implied change in shortwave shows a similar overestimate in forcing due to adjustments by the UM. Observations also imply that aerosol-cloud adjustments in the UM GA7.1 occur in the wrong regime. Adjustments in the UM favor warmer SSTs and lower WVP, while the observations favor colder SSTs and higher WVP. This difference in regime may be due to early precipitation onset in the UM GA7.1.

The present study and McCoy et al. (2018b) project a negative forcing due to adjustments in the midlatitudes. Extension of this study to the subtropics and tropics is reserved for a future analysis. While extrapolating the present results to the tropics is difficult, it seems reasonable to suppose that the pattern of adjustments in the subtropics is relatively similar to the inter-cyclone regime analyzed here and to expect a negative forcing in this region due to adjustments, although this may be weaker than the midlatitude adjustments due to decreasing LWP for increasing $N_{\mathrm{d}}$ over higher SSTs and lower WVP over some of the subtropics (Fig. 8d). One important limitation of this study is that it assumes weak feedbacks between adjustments and scavenging. If some regimes have very strong feedback between precipitation and adjustments, then our analysis will infer adjustments that are too weak.

Our result is in contradiction with previous empirical constraint studies that have postulated that changes in $N_{\mathrm{d}}$ greatly enhance LWP (Rosenfeld et al., 2019), have little effect (Malavelle et al., 2017; Toll et al., 2017), or reduce LWP (Sato et al., 2018; Gryspeerdt et al., 2019). We suggest that this diversity within the literature is because a range of constraints may be arrived at, depending on the degree to which precipitation scavenging and meteorological driving of aerosol and cloud occludes aerosol-cloud adjustments and the steps that are taken in the analysis to account for scavenging-induced and meteorologically induced covariability. Based on the analysis presented here we believe that positive, zero, or extremely strongly negative radiative forcings due to aerosol-cloud adjustments in the midlatitudes are not supported by the observations.

Data availability. MERRA-2 data were downloaded from the Giovanni data server (https://disc.gsfc.nasa.gov/datasets/ M2T1NXSLV_V5.12.4/summary?keywords=merra-2; last access: 22 July 2019; Global Modeling and Assimilation Office, 2015). CERES data were downloaded through the ordering interface at https://ceres.larc.nasa.gov/order_data.php (last access: 22 July 2019) (Doelling et al., 2019).

Supplement. The supplement related to this article is available online at: https://doi.org/10.5194/acp-20-4085-2020-supplement.

Author contributions. All authors contributed ideas and helped with editing the paper. DTM and PF planned the paper. Data analysis and writing were undertaken by DTM. Present-day and preindustrial simulation suites were set up by HG. Simulations were run by DTM. Idealized simulations were set up by DTM. Development of simulations was conducted by HG, PF, DPG, and DTM. MODIS data were created by DPG. MAC-LWP data were created by GSE.

Competing interests. The authors declare that they have no conflict of interest.

Acknowledgements. We acknowledge use of the MONSooN system, a collaborative facility supplied under the Joint Weather and Climate Research Programme, a strategic partnership between the Met Office and the Natural Environment Research Council.

Financial support. Daniel T. McCoy and Paul Field have been supported by the European Commission, Horizon 2020 Framework Programme (PRIMAVERA (grant no. 641727)). Gregory S. Elsaesser has been supported by the Jet Propulsion Laboratory (NASA MEaSUREs (grant no. GG008658)). Hamish Gordon has been 
supported by the Natural Environment Research Council (NERC) (grant no. NE/L013479/1).

Review statement. This paper was edited by Patrick Chuang and reviewed by two anonymous referees.

\section{References}

Ackerman, A. S., Kirkpatrick, M. P., Stevens, D. E., and Toon, O. B.: The impact of humidity above stratiform clouds on indirect aerosol climate forcing, Nature, 432, 1014-1017, https://doi.org/10.1038/nature03174, 2004.

Albrecht, B. A.: Aerosols, Cloud Microphysics, and Fractional Cloudiness, Science, 245, 1227-1230, https://doi.org/10.1126/science.245.4923.1227, 1989.

Andersen, H., Cermak, J., Fuchs, J., Knutti, R., and Lohmann, U.: Understanding the drivers of marine liquid-water cloud occurrence and properties with global observations using neural networks, Atmos. Chem. Phys., 17, 9535-9546, https://doi.org/10.5194/acp-17-9535-2017, 2017.

Ayers, G. P. and Gras, J. L.: Seasonal relationship between cloud condensation nuclei and aerosol methanesulphonate in marine air, Nature, 353, 834-835, 1991.

Bellouin, N., Quaas, J., Gryspeerdt, E., Kinne, S., Stier, P., Watson-Parris, D., Boucher, O., Carslaw, K. S., Christensen, M., Daniau, A. L., Dufresne, J. L., Feingold, G., Fiedler, S., Forster, P., Gettelman, A., Haywood, J. M., Lohmann, U., Malavelle, F., Mauritsen, T., McCoy, D. T., Myhre, G., Mülmenstädt, J., Neubauer, D., Possner, A., Rugenstein, M., Sato, Y., Schulz, M., Schwartz, S. E., Sourdeval, O., Storelvmo, T., Toll, V., Winker, D., and Stevens, B.: Bounding Global Aerosol Radiative Forcing of Climate Change, Rev. Geophys., 58, https://doi.org/10.1029/2019rg000660, 2020.

Bender, F.-M., Frey, L., McCoy, D. T., Grosvenor, D. P., and Mohrmann, J. K.: Assessment of aerosol-cloud-radiation correlations in satellite observations, climate models and reanalysis, Clim. Dynam., 52, 4371-4392, 2019.

Bennartz, R., Fan, J., Rausch, J., Leung, L. R., and Heidinger, A. K.: Pollution from China increases cloud droplet number, suppresses rain over the East China Sea, Geophys. Res. Lett., 38, L09704, https://doi.org/10.1029/2011gl047235, 2011.

Berner, A. H., Bretherton, C. S., Wood, R., and Muhlbauer, A.: Marine boundary layer cloud regimes and POC formation in a CRM coupled to a bulk aerosol scheme, Atmos. Chem. Phys., 13, 12549-12572, https://doi.org/10.5194/acp-13-125492013, 2013.

Bodas-Salcedo, A., Webb, M. J., Bony, S., Chepfer, H., Dufresne, J. L., Klein, S. A., Zhang, Y., Marchand, R., Haynes, J. M., Pincus, R., and John, V. O.: COSP: Satellite simulation software for model assessment, B. Am. Meteorol. Soc., 92, 1023-1043, https://doi.org/10.1175/2011BAMS2856.1, 2011.

Bodas-Salcedo, A., Williams, K. D., Ringer, M. A., Beau, I., Cole, J. N. S., Dufresne, J. L., Koshiro, T., Stevens, B., Wang, Z., and Yokohata, T.: Origins of the Solar Radiation Biases over the Southern Ocean in CFMIP2 Models, J. Climate, 27, 41-56, https://doi.org/10.1175/jcli-d-13-00169.1, 2014.
Boutle, I. A., Abel, S. J., Hill, P. G., and Morcrette, C. J.: Spatial variability of liquid cloud and rain: observations and microphysical effects, Q. J. Roy. Meteor. Soc., 140, 583-594, https://doi.org/10.1002/qj.2140, 2014.

Bretherton, C. S. and Blossey, P. N.: Low cloud reduction in a greenhouse-warmed climate: Results from Lagrangian LES of a subtropical marine cloudiness transition, J. Adv. Model. Earth Sy., 6, 91-114, https://doi.org/10.1002/2013MS000250, 2014.

Bretherton, C. S., Blossey, P. N., and Uchida, J.: Cloud droplet sedimentation, entrainment efficiency, and subtropical stratocumulus albedo, Geophys. Res. Lett., 34, L03813, https://doi.org/10.1029/2006g1027648, 2007.

Charlson, R. J., Lovelock, J. E., Andreae, M. O., and Warren, S. G.: Oceanic phytoplankton, atmospheric sulfur, cloud albedo and climate, Nature, 326, 655-661, https://doi.org/10.1038/326655a0, 1987.

Chen, Y.-C., Christensen, M. W., Stephens, G. L., and Seinfeld, J. H.: Satellite-based estimate of global aerosol-cloud radiative forcing by marine warm clouds, Nat. Geosci., 7, 643-646, https://doi.org/10.1038/ngeo2214, 2014.

Christensen, M. W., Neubauer, D., Poulsen, C. A., Thomas, G. E., McGarragh, G. R., Povey, A. C., Proud, S. R., and Grainger, R. G.: Unveiling aerosol-cloud interactions - Part 1: Cloud contamination in satellite products enhances the aerosol indirect forcing estimate, Atmos. Chem. Phys., 17, 13151-13164, https://doi.org/10.5194/acp-17-13151-2017, 2017.

Doelling, D. R., Loeb, N. G., Keyes, D. F., Nordeen, M. L., Morstad, D., Nguyen, C., Wielicki, B. A., Young, D. F., and Sun, M.: Geostationary Enhanced Temporal Interpolation for CERES Flux Products, J. Atmos. Ocean. Tech., 30, 1072-1090, https://doi.org/10.1175/jtech-d-12-00136.1, 2013 (data available at: https://ceres.larc.nasa.gov/order_data.php, last access: 22 July 2019).

Dong, X., Xi, B., and Wu, P.: Investigation of the Diurnal Variation of Marine Boundary Layer Cloud Microphysical Properties at the Azores, J. Climate, 27, 8827-8835, https://doi.org/10.1175/jclid-14-00434.1, 2014.

Elsaesser, G. S., O’Dell, C. W., Lebsock, M. D., Bennartz, R., Greenwald, T. J., and Wentz, F. J.: The Multi-Sensor Advanced Climatology of Liquid Water Path (MAC-LWP), J. Climate, 30, https://doi.org/10.1175/jcli-d-16-0902.1, 2017.

Eyring, V., Bony, S., Meehl, G. A., Senior, C. A., Stevens, B., Stouffer, R. J., and Taylor, K. E.: Overview of the Coupled Model Intercomparison Project Phase 6 (CMIP6) experimental design and organization, Geosci. Model Dev., 9, 1937-1958, https://doi.org/10.5194/gmd-9-1937-2016, 2016.

Field, P. R. and Wood, R.: Precipitation and cloud structure in midlatitude cyclones, J. Climate, 20, 233-254, https://doi.org/10.1175/jcli3998.1, 2007.

Forster, P. M.: Inference of climate sensitivity from analysis of Earth's energy budget, Annu. Rev. Earth Pl. Sc., 44, 85-106, 2016.

Gettelman, A., Morrison, H., Terai, C. R., and Wood, R.: Microphysical process rates and global aerosol-cloud interactions, Atmos. Chem. Phys., 13, 9855-9867, https://doi.org/10.5194/acp13-9855-2013, 2013.

Global Modeling and Assimilation Office (GMAO): MERRA2 tavg1_2d_slv_Nx: 2d,1-Hourly,Time-Averaged,SingleLevel,Assimilation,Single-Level Diagnostics V5.12.4, 
Greenbelt, MD, USA, Goddard Earth Sciences Data and Information Services Center (GES DISC), https://doi.org/10.5067/VJAFPLI1CSIV, 2015.

Granier, C., Lamarque, J. F., Mieville, A., Muller, J. F., Olivier, J., Orlando, J., Peters, J., Petron, G., Tyndall, G., and Wallens, S.: POET, a database of surface emissions of ozone precursors, available at: http://accent.aero.jussieu.fr/POET_metadata. php (last access: 30 March 2020), 2005.

Grosvenor, D. P. and Wood, R.: The effect of solar zenith angle on MODIS cloud optical and microphysical retrievals within marine liquid water clouds, Atmos. Chem. Phys., 14, 7291-7321, https://doi.org/10.5194/acp-14-7291-2014, 2014.

Grosvenor, D. P., Sourdeval, O., Zuidema, P., Ackerman, A., Alexandrov, M. D., Bennartz, R., Boers, R., Cairns, B., Chiu, J. C., Christensen, M., Deneke, H., Diamond, M., Feingold, G., Fridlind, A., Hünerbein, A., Knist, C., Kollias, P., Marshak, A., McCoy, D., Merk, D., Painemal, D., Rausch, J., Rosenfeld, D., Russchenberg, H., Seifert, P., Sinclair, K., Stier, P., van Diedenhoven, B., Wendisch, M., Werner, F., Wood, R., Zhang, Z., and Quaas, J.: Remote Sensing of Droplet Number Concentration in Warm Clouds: A Review of the Current State of Knowledge and Perspectives, Rev. Geophys., 56, 409-453, https://doi.org/10.1029/2017rg000593, 2018.

Gryspeerdt, E., Quaas, J., and Bellouin, N.: Constraining the aerosol influence on cloud fraction, J. Geophys. Res.-Atmos., 121, 35663583, https://doi.org/10.1002/2015JD023744, 2016.

Gryspeerdt, E., Goren, T., Sourdeval, O., Quaas, J., Mülmenstädt, J., Dipu, S., Unglaub, C., Gettelman, A., and Christensen, M.: Constraining the aerosol influence on cloud liquid water path, Atmos. Chem. Phys., 19, 5331-5347, https://doi.org/10.5194/acp19-5331-2019, 2019.

Hartmann, D. L. and Short, D. A.: On the Use of Earth Radiation Budget Statistics for Studies of Clouds and Climate, J. Atmos. Sci., 37, 1233-1250, https://doi.org/10.1175/15200469(1980)037< 1233:OTUOER> 2.0.CO;2, 1980.

Jing, X. and Suzuki, K.: The Impact of Process-Based Warm Rain Constraints on the Aerosol Indirect Effect, Geophys. Res. Lett., 45, 10,729-710,737, https://doi.org/10.1029/2018gl079956, 2018.

Jing, X., Suzuki, K., and Michibata, T.: The Key Role of Warm Rain Parameterization in Determining the Aerosol Indirect Effect in a Global Climate Model, J. Climate, 32, 4409-4430, https://doi.org/10.1175/jcli-d-18-0789.1, 2019.

Khairoutdinov, M. and Kogan, Y.: A new cloud physics parameterization in a large-eddy simulation model of marine stratocumulus, Mon. Weather Rev., 128, 229-243, 2000.

King, M. D., Menzel, W. P., Kaufman, Y. J., Tanre, D., BoCai, G., Platnick, S., Ackerman, S. A., Remer, L. A., Pincus, R., and Hubanks, P. A.: Cloud and aerosol properties, precipitable water, and profiles of temperature and water vapor from MODIS, IEEE T. Geosci. Remote, 41, 442-458, https://doi.org/10.1109/TGRS.2002.808226, 2003.

Klein, S. A. and Hartmann, D. L.: The Seasonal Cycle of Low Stratiform Clouds, J. Climate, 6, 1587-1606, https://doi.org/10.1175/1520-0442(1993)006< 1587:tscols> 2.0.co;2, 1993.

Klein, S. A., Hall, A., Norris, J. R., and Pincus, R.: Low-Cloud Feedbacks from Cloud-Controlling Factors: A Review, Surv.
Geophys., 38, 1307-1329, https://doi.org/10.1007/s10712-0179433-3, 2017.

Ma, P.-L., Rasch, P. J., Chepfer, H., Winker, D. M., and Ghan, S. J.: Observational constraint on cloud susceptibility weakened by aerosol retrieval limitations, Nat. Commun., 9, 2640, https://doi.org/10.1038/s41467-018-05028-4, 2018.

Malavelle, F. F., Haywood, J. M., Jones, A., Gettelman, A., Clarisse, L., Bauduin, S., Allan, R. P., Karset, I. H. H., Kristjánsson, J. E., Oreopoulos, L., Cho, N., Lee, D., Bellouin, N., Boucher, O., Grosvenor, D. P., Carslaw, K. S., Dhomse, S., Mann, G. W., Schmidt, A., Coe, H., Hartley, M. E., Dalvi, M., Hill, A. A., Johnson, B. T., Johnson, C. E., Knight, J. R., O'Connor, F. M., Partridge, D. G., Stier, P., Myhre, G., Platnick, S., Stephens, G. L., Takahashi, H., and Thordarson, T.: Strong constraints on aerosol-cloud interactions from volcanic eruptions, Nature, 546, 485-491, https://doi.org/10.1038/nature22974, http://www.nature.com/nature/journal/v546/n7659/abs/ nature22974.html\#supplementary-information, 2017.

Mauger, G. S. and Norris, J. R.: Meteorological bias in satellite estimates of aerosol-cloud relationships, Geophys. Res. Lett., 34, L16824, https://doi.org/10.1029/2007g1029952, 2007.

McComiskey, A. and Feingold, G.: The scale problem in quantifying aerosol indirect effects, Atmos. Chem. Phys., 12, 1031-1049, https://doi.org/10.5194/acp-12-1031-2012, 2012.

McCoy, D. T., Burrows, S. M., Wood, R., Grosvenor, D. P., Elliott, S. M., Ma, P. L., Rasch, P. J., and Hartmann, D. L.: Natural aerosols explain seasonal and spatial patterns of Southern Ocean cloud albedo, Science Advances, 1, e1500157, https://doi.org/10.1126/sciadv.1500157, 2015a.

McCoy, D. T., Hartmann, D. L., Zelinka, M. D., Ceppi, P., and Grosvenor, D. P.: Mixed-phase cloud physics and Southern Ocean cloud feedback in climate models, J. Geophys. Res.Atmos., 120, 9539-9554, https://doi.org/10.1002/2015jd023603, 2015b.

McCoy, D. T., Tan, I., Hartmann, D. L., Zelinka, M. D., and Storelvmo, T.: On the relationships among cloud cover, mixed-phase partitioning, and planetary albedo in GCMs, J. Adv. Model. Earth Sy., 8, 650-668, https://doi.org/10.1002/2015ms000589, 2016.

McCoy, D. T., Eastman, R., Hartmann, D. L., and Wood, R.: The Change in Low Cloud Cover in a Warmed Climate Inferred from AIRS, MODIS, and ERA-Interim, J. Climate, 30, 3609-3620, https://doi.org/10.1175/jcli-d-15-0734.1, 2017.

McCoy, D. T., Bender, F. A.-M., Grosvenor, D. P., Mohrmann, J. K., Hartmann, D. L., Wood, R., and Field, P. R.: Predicting decadal trends in cloud droplet number concentration using reanalysis and satellite data, Atmos. Chem. Phys., 18, 2035-2047, https://doi.org/10.5194/acp-18-2035-2018, 2018 a.

McCoy, D. T., Field, P. R., Schmidt, A., Grosvenor, D. P., Bender, F. A.-M., Shipway, B. J., Hill, A. A., Wilkinson, J. M., and Elsaesser, G. S.: Aerosol midlatitude cyclone indirect effects in observations and high-resolution simulations, Atmos. Chem. Phys., 18, 5821-5846, https://doi.org/10.5194/acp-185821-2018, 2018b.

McCoy, D. T., Field, P. R., Elsaesser, G. S., Bodas-Salcedo, A., Kahn, B. H., Zelinka, M. D., Kodama, C., Mauritsen, T., Vanniere, B., Roberts, M., Vidale, P. L., Saint-Martin, D., Voldoire, A., Haarsma, R., Hill, A., Shipway, B., and Wilkinson, J.: Cloud feedbacks in extratropical cyclones: insight from long- 
term satellite data and high-resolution global simulations, Atmos. Chem. Phys., 19, 1147-1172, https://doi.org/10.5194/acp19-1147-2019, 2019.

Michibata, T., Suzuki, K., Sekiguchi, M., and Takemura, T.: Prognostic Precipitation in the MIROC6-SPRINTARS GCM: Description and Evaluation Against Satellite Observations, J. Adv. Model. Earth Sy., 11, 839-860, https://doi.org/10.1029/2018ms001596, 2019.

Miyamoto, A., Nakamura, H., and Miyasaka, T.: Influence of the Subtropical High and Storm Track on Low-Cloud Fraction and Its Seasonality over the South Indian Ocean, J. Climate, 31, 4017-4039, https://doi.org/10.1175/jcli-d-17-0229.1, 2018.

Molod, A., Takacs, L., Suarez, M., and Bacmeister, J.: Development of the GEOS-5 atmospheric general circulation model: evolution from MERRA to MERRA2, Geosci. Model Dev., 8, 1339-1356, https://doi.org/10.5194/gmd-8-1339-2015, 2015.

Mulcahy, J. P., Jones, C., Sellar, A., Johnson, B., Boutle, I. A., Jones, A., Andrews, T., Rumbold, S. T., Mollard, J., Bellouin, N., Johnson, C. E., Williams, K. D., Grosvenor, D. P., and McCoy, D. T.: Improved Aerosol Processes and Effective Radiative Forcing in HadGEM3 and UKESM1, J. Adv. Model. Earth Sy., 10, 2786-2805, https://doi.org/10.1029/2018MS001464, 2018.

Myers, T. A. and Norris, J. R.: Observational Evidence That Enhanced Subsidence Reduces Subtropical Marine Boundary Layer Cloudiness, J. Climate, 26, 7507-7524, https://doi.org/10.1175/JCLI-D-12-00736.1, 2013.

Myers, T. A. and Norris, J. R.: On the Relationships between Subtropical Clouds and Meteorology in Observations and CMIP3 and CMIP5 Models, J. Climate, 28, 2945-2967, https://doi.org/10.1175/JCLI-D-14-00475.1, 2015.

Myhre, G., Samset, B. H., Schulz, M., Balkanski, Y., Bauer, S., Berntsen, T. K., Bian, H., Bellouin, N., Chin, M., Diehl, T., Easter, R. C., Feichter, J., Ghan, S. J., Hauglustaine, D., Iversen, T., Kinne, S., Kirkevåg, A., Lamarque, J.-F., Lin, G., Liu, X., Lund, M. T., Luo, G., Ma, X., van Noije, T., Penner, J. E., Rasch, P. J., Ruiz, A., Seland, Ø., Skeie, R. B., Stier, P., Takemura, T., Tsigaridis, K., Wang, P., Wang, Z., Xu, L., Yu, H., Yu, F., Yoon, J.-H., Zhang, K., Zhang, H., and Zhou, C.: Radiative forcing of the direct aerosol effect from AeroCom Phase II simulations, Atmos. Chem. Phys., 13, 1853-1877, https://doi.org/10.5194/acp13-1853-2013, 2013.

Pincus, R. and Baker, M. B.: Effect of precipitation on the albedo susceptibility of clouds in the marine boundary layer, Nature, 372, 250-252, https://doi.org/10.1038/372250a0, 1994.

Possner, A., Wang, H., Wood, R., Caldeira, K., and Ackerman, T. P.: The efficacy of aerosol-cloud radiative perturbations from nearsurface emissions in deep open-cell stratocumuli, Atmos. Chem. Phys., 18, 17475-17488, https://doi.org/10.5194/acp-18-174752018, 2018.

Qu, X., Hall, A., Klein, S. A., DeAngelis, and Anthony, M.: Positive tropical marine low-cloud cover feedback inferred from cloud-controlling factors, Geophys. Res. Lett., 42, 7767-7775, https://doi.org/10.1002/2015GL065627, 2015.

Rosenfeld, D., Zhu, Y., Wang, M., Zheng, Y., Goren, T., and Yu, S.: Aerosol-driven droplet concentrations dominate coverage and water of oceanic low-level clouds, Science, 363, eaav0566, https://doi.org/10.1126/science.aav0566, 2019.

Sato, Y., Goto, D., Michibata, T., Suzuki, K., Takemura, T., Tomita, H., and Nakajima, T.: Aerosol effects on cloud water amounts were successfully simulated by a global cloud-system resolving model, Nat. Commun., 9, 985, https://doi.org/10.1038/s41467018-03379-6, 2018.

Seethala, C., Norris, J. R., and Myers, T. A.: How Has Subtropical Stratocumulus and Associated Meteorology Changed since the 1980s?, J. Climate, 28, 8396-8410, https://doi.org/10.1175/JCLI-D-15-0120.1, 2015.

Senior, C. A. and Mitchell, J. F. B.: Carbon-dioxide and Climate - The Impact of Cloud Parameterization, J. Climate, 6, 393-418, https://doi.org/10.1175/1520-0442(1993)006< 0393:cdacti> 2.0.co;2, 1993.

Sindelarova, K., Granier, C., Bouarar, I., Guenther, A., Tilmes, S., Stavrakou, T., Müller, J.-F., Kuhn, U., Stefani, P., and Knorr, W.: Global data set of biogenic VOC emissions calculated by the MEGAN model over the last 30 years, Atmos. Chem. Phys., 14, 9317-9341, https://doi.org/10.5194/acp-14-9317-2014, 2014.

Stevens, B., and Brenguier, J. L.: Cloud controlling factors: Low clouds, in: Clouds in the Perturbed Climate System: Their Relationship to Energy Balance, Atmospheric Dynamics, and Precipitation, MIT Press, Cambridge, Mass., 173-196, 2009.

Stevens, B. and Feingold, G.: Untangling aerosol effects on clouds and precipitation in a buffered system, Nature, 461, 607-613, 2009.

Stier, P., Feichter, J., Kinne, S., Kloster, S., Vignati, E., Wilson, J., Ganzeveld, L., Tegen, I., Werner, M., Balkanski, Y., Schulz, M., Boucher, O., Minikin, A., and Petzold, A.: The aerosol-climate model ECHAM5-HAM, Atmos. Chem. Phys., 5, 1125-1156, https://doi.org/10.5194/acp-5-1125-2005, 2005.

Storelvmo, T.: Aerosol Effects on Climate via Mixed-Phase and Ice Clouds, Annu. Rev. Earth Pl. Sc., 45, 199-222, https://doi.org/10.1146/annurev-earth-060115-012240, 2017.

Tan, I., Storelvmo, T., and Zelinka, M. D.: Observational constraints on mixed-phase clouds imply higher climate sensitivity, Science, 352, 224-227, https://doi.org/10.1126/science.aad5300, 2016.

Toll, V., Christensen, M., Gassó, S., and Bellouin, N.: Volcano and Ship Tracks Indicate Excessive Aerosol-Induced Cloud Water Increases in a Climate Model, Geophys. Res. Lett., 44, 12,492412,500, https://doi.org/10.1002/2017GL075280, 2017.

Toll, V., Christensen, M., Quaas, J., and Bellouin, N.: Weak average liquid-cloud-water response to anthropogenic aerosols, Nature, 572, 51-55, https://doi.org/10.1038/s41586-019-1423-9, 2019.

Tsushima, Y., Emori, S., Ogura, T., Kimoto, M., Webb, M. J., Williams, K. D., Ringer, M. A., Soden, B. J., Li, B., and Andronova, N.: Importance of the mixed-phase cloud distribution in the control climate for assessing the response of clouds to carbon dioxide increase: a multi-model study, Clim. Dynam., 27, 113-126, https://doi.org/10.1007/s00382-006-0127-7, 2006.

Twomey, S.: Influence of pollution on shortwave albedo of clouds, J. Atmos. Sci., 34, 1149-1152, https://doi.org/10.1175/15200469(1977)034< 1149:tiopot> 2.0.co;2, 1977.

Wall, C. J., Hartmann, D. L., and Ma, P.-L.: Instantaneous Linkages between Clouds and Large-Scale Meteorology over the Southern Ocean in Observations and a Climate Model, J. Climate, 30, 9455-9474, https://doi.org/10.1175/jcli-d-17-0156.1, 2017.

Walters, D., Baran, A. J., Boutle, I., Brooks, M., Earnshaw, P., Edwards, J., Furtado, K., Hill, P., Lock, A., Manners, J., Morcrette, C., Mulcahy, J., Sanchez, C., Smith, C., Stratton, R., Tennant, W., Tomassini, L., Van Weverberg, K., Vosper, S., Willett, M., Browse, J., Bushell, A., Carslaw, K., Dalvi, M., Essery, R., Ged- 
ney, N., Hardiman, S., Johnson, B., Johnson, C., Jones, A., Jones, C., Mann, G., Milton, S., Rumbold, H., Sellar, A., Ujiie, M., Whitall, M., Williams, K., and Zerroukat, M.: The Met Office Unified Model Global Atmosphere 7.0/7.1 and JULES Global Land 7.0 configurations, Geosci. Model Dev., 12, 1909-1963, https://doi.org/10.5194/gmd-12-1909-2019, 2019.

Wang, S., Wang, Q., and Feingold, G.: Turbulence, condensation, and liquid water transport in numerically simulated nonprecipitating stratocumulus clouds, J. Atmos. Sci., 60, 262-278, 2003.

Wood, R.: Stratocumulus Clouds, Mon. Weather Rev., 140, 2373 2423, https://doi.org/10.1175/MWR-D-11-00121.1, 2012.
Wood, R. and Bretherton, C. S.: On the relationship between stratiform low cloud cover and lower-tropospheric stability, J. Climate, 19, 6425-6432, https://doi.org/10.1175/jcli3988.1, 2006.

Wood, R., Leon, D., Lebsock, M., Snider, J., and Clarke, A. D.: Precipitation driving of droplet concentration variability in marine low clouds, J. Geophys. Res.-Atmos., 117, D19210, https://doi.org/10.1029/2012jd018305, 2012.

Xue, H. and Feingold, G.: Large-Eddy Simulations of Trade Wind Cumuli: Investigation of Aerosol Indirect Effects, J. Atmos. Sci., 63, 1605-1622, https://doi.org/10.1175/jas3706.1, 2006. 